\title{
Integrated development of glycobiologics: from discovery to applications in the design of nanoparticular drug delivery systems.
}

\author{
Christine Vauthier*, Isabelle Bertholon, Denis Labarre
}

Physicochimie, Pharmacotechnie et Biopharmacie, UMR CNRS 8612, Université de Paris XI, Faculté de Pharmacie, 5, Rue J.B. Clément, 92296 Chatenay Malabry Cedex France

Published in: "Handbook of Pharmaceutical Biotechnology", Shayne Cox Gad Ph.D., D.A.B.T., Editors, ISBN:9780471213864, John Wiley and Sons Inc., Hoboken, New Jersey 2007. Chap. 1.4 pp. 125-160.. https://doi.org/10.1002/9780470117118.ch1d

\section{Corresponding author :}

Physicochimie, Pharmacotechnie et Biopharmacie, UMR CNRS 8612, Université de Paris XI, Faculté de Pharmacie, 5, Rue J.B. Clément 92296 Chatenay-Malabry Cedex France

E-mail : christine.vauthier@u-psud.fr

\begin{abstract}
From the three major classes of biomolecules including proteins, nucleic acids and carbohydrates, the carbohydrates are, at the moment, the least exploited. The recent development of operating methods for the analysis of carbohydrates and for the synthesis of oligosaccharides supports the efforts made to investigate the roles of carbohydrates in biological phenomena. Research on carbohydrates is very active leading to discovery of new oligosaccharides and functions almost everyday as witnesses by the amount of papers published every month. The purpose of this chapter is to point out some of the functions of carbohydrates that have been identified and that may be interesting to integrate within the design of nanoparticulate drug carriers able to carry and target a drug to the diseased organs or cells. The complete control of the biodistribution of these systems which is mainly governed by their surface properties remains one of the major challenges to achieve. Among the different strategies proposed so far, it has been suggested to coat the nanoparticulate drug carriers with polysaccharides in order to mimic the surface of cells, bacteria or viruses and to confer the nanoparticles new surface properties including the biological activities of the carbohydrates. The coating of nanoparticulate drug carriers with certain types of carbohydrates may be interesting to give the nanoparticles specific recognition or signalling functions to improve their targeting specificity and efficiency. Other carbohydrates display very specific biological activities that may be interesting to combine with nanoparticulate drug carriers to create biologically active nanoparticulate systems. Many other examples will be discussed in this chapter and the benefit of the approach will be examined with the few examples of nanoparticulate drug carriers already developed on this basis.
\end{abstract}

Key words: carbohydrate-based nanoparticles, nanoparticle drug carriers, targeting, bioadhesion, Glycobiologic integrated development, 


\section{CONTENT}

1 INTRODUCTION

2 CARBOHYDRATE RESEARCH: MAIN STEPS OF DEVELOPMENT AND DISCOVERY OF THEIR FUNCTIONALITIES. 3

3 DEVELOPMENT OF NANOPARTICULAR DRUG CARRIERS: PRESENT STATES AND LIMITATIONS 5

4 INTEGRATION OF CARBOHYDRATE IN THE DESIGN OF NANOPARTICLE DRUG CARRIERS WITH NEW FUNCTIONALITIES. 6

4.1 Carbohydrates to improve mucoadhesion of nanoparticle drug carriers. 6

4.2 Use of carbohydrates to control the fate of drug carrier after intravenous administration.

$\begin{array}{lll}4.3 & \text { Carbohydrates and drug carrier targeting perspectives. } & 9\end{array}$

5 ENHANCEMENT OF CARBOHYDRATE THERAPEUTIC ACTIVITY BY ASSOCIATION WITH NANOPARTICLE DELIVERY SYSTEMS.

$\begin{array}{lll}5.1 & \text { Anti-infectious agents } & 13\end{array}$

$\begin{array}{lll}5.2 & \text { Anticancer activity } & 15\end{array}$

$\begin{array}{lll}\text { 5.3 Control of vascular smooth muscle cell proliferation } & 15\end{array}$

5.4 Activity on the immune system 16

$\begin{array}{lll}\text { 5.5 Control of blood coagulation and complement activation } & 17\end{array}$

6 NANOPARTICLE DRUG CARRIERS MADE OF CARBOHYDRATES FOR THE DELIVERY OF FRAGILE MOLECULES 18

$\begin{array}{llr}7 \text { CONCLUSION } & 20\end{array}$

8 REFERENCES $\quad 21$ 
Author version from Vauthier et al., In "Handbook of Pharmaceutical Biotechnology", 2007. https://doi.org/10.1002/9780470117118.ch1d

\section{INTRODUCTION}

From the three major classes of biomolecules including proteins, nucleic acids and carbohydrates, the carbohydrates entering the constitution of glycans and polysaccharides are, at the moment, the least exploited in biology. The recent development of operating methods for the analysis of carbohydrates and for the synthesis of oligosaccharides support the efforts made to investigate the roles of carbohydrates in biological phenomena [1-4]. Different already identified functions of carbohydrates may be interesting to be integrated within drug delivery systems conferring new properties and opening avenues for innovative developments. In this view, carbohydrates may be used either as a drug due to their own biological activities or as molecules to design nanoparticles with new functionalities [5-8]. Developing drug delivery systems, the main challenge is to design systems able to carry and target a drug to the diseased organs or cells after administration in the body by the appropriate route $[6,7,9,10]$. This assumes that the biodistribution of the carrier system is perfectly controlled after in vivo administration. In the case of soluble carrier, this can be achieved by grafting define types of carbohydrate ligands on the polymer backbone $[10,11]$. Using colloidal particles like liposomes and polymer nanoparticles, it is now well accepted that their biodistribution is mainly controlled by their surface properties [9, 12-15]. Several carbohydrates and polysaccharides were identified at the surface of cells, bacteria and viruses as having a key role in biological recognition and signalling events. Therefore, the potential of their use as coating material or as ligands to promote specific recognition between carrier and target cells was carefully considered as a possible way to develop biomimetic drug delivery systems having different functionalities [16-24]. In this chapter, we will summarize the main stages of the development of carbohydrates and polysaccharides as components of interest to be used either as a targeted drug or as a component entering the design of drug delivery systems. The first part of the chapter will be focused on the principal milestones which allowed discovery of most of the carbohydrates and polysaccharides known today in terms of their chemical analysis and biological activity investigations. This part will also present status about the chemical synthesis of these compounds. The second part of the chapter will briefly discuss the present state and limitations to the developments of nanoparticle drug carriers. Integration of carbohydrate and polysaccharide developments in the design of drug delivery systems with new functionalities will constitute the third part of the chapter. The fourth and the fifth parts will respectively review the current research about applications of nanoparticles as delivery systems for biologically active carbohydrates and the use of nanoparticle drug carriers made of polysaccharides for the delivery of fragile bioactive molecules.

\section{CARBOHYDRATE RESEARCH: MAIN STEPS OF DEVELOPMENT AND DISCOVERY OF THEIR FUNCTIONALITIES.}

Forty years ago, Eylar [25] suggested for the first time that the carbohydrate units found in biologically active glycoproteins could act as a kind of "chemical label" or "chemical passport" to promote specific interactions of glycoproteins with corresponding cell surface receptors to achieve their transportation across the cell membrane. However, progresses in the understanding of the biological role of glycan moieties included in biological structures was hampered for long considering that glycans and polysaccharides were much more complex structures to study than proteins and nucleic acids. Thus, it is only 30 years ago, while full chemical synthesis of peptides was already possible and those of nucleic acid was in its infant age, that various carbohydrate containing compounds came into light as important elements in numbers of biological activities [26-30]. For instance, the years 1976 to 1983 were critical in the discovery of the antithrombine binding site of heparin which now can be used to confer anti-clotting and anti-complement activation properties to drug carrier systems [30-32]. The study of lectines isolated from animals which are now known to be involved in many of the biological recognition molecules involving carbohydrates started to grow rapidly in the 1980s thanks to the development of recombination techniques to produce them [28]. 
Author version from Vauthier et al., In "Handbook of Pharmaceutical Biotechnology", 2007. https://doi.org/10.1002/9780470117118.ch1d

Identification of the role of these molecules in recognition phenomena as well as understanding their functionality are interesting to be able to promote specific recognition between target cells and drug delivery systems achieving drug targeting. It is also noteworthy to point out the discovery of carbohydrates and carbohydrate derivatives which are currently used as major anticancer drugs and antibiotics in clinics [33-35]. Because of the high toxicity of these compounds for the healthy tissues, they are good drug candidates to be incorporated in nanoparticle drug carrier systems improving their specific biodistribution.

For long, progresses in glycobiology were hampered due to technological difficulties on analytical order. The appearance of the high-performance anion-exchange chromatography (HPAEC) in the mid 1990s revolution the analytical capacity and considerably improved precision about the determination of carbohydrate sequences and arrangements in glycans isolated from glycosylated biological compounds $[2,4]$. This was a considerable millestone being completed which boost the resolution of glycan structures and in parallel open new areas to further investigate their biological activity. The analytical techniques were constantly improved by the successive introduction of the pulsed amperometry detection (PAD) and more recently by on-line coupling the HPAEC to mass spectrometry devices and NMR methods using a nano-probe [3, 4, 36-38]. New methodologies continue to be developed improving performance of the existing analytical methods [39]. The introduction of screening methods using microarray and chip technologies appeared within the last 3 years accelerating discovery and progress towards the understanding of the role of carbohydrates in biology $[29,40,41]$.

Research into the biological roles of carbohydrates may be possible owing the fact that sufficient quantities may be isolated from natural extract. Because of their structural complexity, it is extremely difficult to isolate pure carbohydrates from natural sources. Progresses in the analytical chromatographic methods help improving preparative techniques providing purified fractions of defined glycans from various natural extracts [36, 42]. However, the only way to access to very pure carbohydrates relies on their chemical or enzymatic synthesis which also constitutes the more attractive route for the production of the sufficient quantities for biological studies designed to identify biological roles and eventually medicinal interests. The synthesis of polysaccharides and glycans was an important technological challenge. The intensive efforts based on innovative strategies lead to major advances making now possible the synthesis of rather complex carbohydrates [1, 43-45]. Stereoregular polysaccharides including linear, branched, amino and deoxy polysaccharides can be synthesized by ring opening polymerization of anhydro-sugar derivatives [1]. The technically extremely difficult synthesis of highly branched carbohydrates was made possible with the development of solid phase synthesis strategies [44]. Another important milestone was completed thanks to the recent development of an automated oligosaccharide synthesizer leading to an accelerated access to many highly branched carbohydrates for identification of their biological function [44]. Even if this methodology provides just enough amount of glycan to study the biological role of the product, this really opens avenues for the identification and creation of important compounds for future biochemical and medicinal applications [44]. For instance, after years of research, many synthetic heparins proposed as anticoagulant drugs can be synthesized on a production scale. They are currently at different stages of clinical development [46]. The chemistry remains complicated and some synthetic routes which have been scaled up comprised up to 65 steps. 
Author version from Vauthier et al., In "Handbook of Pharmaceutical Biotechnology", 2007.

\section{DEVELOPMENT OF NANOPARTICULAR DRUG CARRIERS: PRESENT STATES AND LIMITATIONS}

Despite several advances in chemotherapy, the real therapy of cancer and major infections still remain a challenge. One problem comes from the nonspecific drug distribution resulting in low tumour or infected tissue concentrations and systemic toxicity. Another problem comes from the lack of stability of drugs in biological media and their incapacity to cross biological barriers. To improve drug concentration in the targeted tissues, several approaches have been suggested including the association of the drug to carrier systems. A large piece of work has been done using liposomes as carriers which lead to the several marketed formulations so far. For instance, the liposomal formulation of Amphotericin B which is the leading compounds in the treatment of leishmaniasis is today the more efficient treatment against this parasite and other fungal infections [47]. The toxicity of Amphotericin B was reduced by a factor of 50 to 70-fold which is among the most obvious benefit for the use of this liposome formulation in clinics [48]. The main drawback of liposomes remains the cost of the phospholipids entering their composition. To reduce cost, the biggest challenge is believed to come from polymer nanoparticles. Indeed, polymers are much cheaper material compared to phospholipids and methods for producing nanoparticles are generally simpler. Other advantages of the polymer systems are their higher stability in biological media especially for the administration of drugs by mucosal routes and upon slight changes in the formulation. Additionally, they should be theoretically tailor made thanks to the progress in colloid and polymer technology [9, 49]. However, only a couple of polymers are suitable as main components of the polymer nanoparticles designed as drug carrier systems [6, 7, 9]. As for liposomes, polymer nanoparticles were developed as drug carriers to improve the efficacy of the associated drug thanks to a better control of its biodistribution towards the diseased organ or cells and to their faculty to overcome biological barriers [9, 50, 51]. These colloidal particles have demonstrated enhanced efficacy for numerous drugs compared to conventional formulations. Indeed, the biological activity of the drug associated with the carrier is generally improved while the side effects due to their toxicity are reduced thanks to a better control of the biodistribution [52-56]. The improved efficacy can also be explained by a higher stability of the drug in biological media and ability to overcome biological barriers. However, the main limitation of these systems remains the full control of their biodistribution because they still lack of very precise targeting specificities. This is the main challenge which remains to be addressed. According to our present knowledge, a better control of the interactions between the drug delivery system and surrounded biological media should improve targeting efficacy as well as promoting occurrence of highly specific interactions. Thus, it was postulated that the control of the biodistribution of drug carriers could be possible by modifying and by adjusting the surface characteristics of the drug delivery systems. The modification of surface properties of drug delivery systems by coating with poly(ethylene glycol) actually rerouted the carrier from a very efficient recognition and uptake by macrophages of the MPS towards long circulating particles in the blood stream $[58,59]$. It is now admitted that the biodistribution of a drug carrier greatly depends on the nonspecific and specific interactions between its exposed surface and the biological components of the surrounded medium found either in blood, on the cell surface or at the level of biological barriers i.e. endothelium or mucosa. Thus, efforts are now carried on tailoring the design of the carrier surface [12].

To be used as drug carriers, different drugs should be incorporated in the nanoparticles. Most of the nanoparticles made of synthetic polymers including polyesters or polyanhydrides and poly(aminoacids) can incorporate enough amount of lipophilic drugs. However, they are totally inefficient to incorporate hydrophilic molecules such as peptides, proteins or nucleic acids. These molecules with a high therapeutic potential hardly cross biological barriers. They need to be associated with a drug carrier enhancing their transport across the biological barriers and preserving their biological activity because there are highly unstable in biological media. This problem could be 
Author version from Vauthier et al., In "Handbook of Pharmaceutical Biotechnology", 2007. https://doi.org/10.1002/9780470117118.ch1d

solved using nanoparticles made of poly(alkylcyanoacrylate) [60]. Polysaccharides extracted from natural compound could also be used to formulate new types of drug delivery systems in which macromolecules from biotechnology could be incorporated [6-8, 61, 62].

\section{INTEGRATION OF CARBOHYDRATE IN THE DESIGN OF NANOPARTICLE DRUG CARRIERS WITH NEW FUNCTIONALITIES.}

As mentioned above, interactions of nanoparticle drug carriers with the surrounded biological environment are key factors controlling the in vivo fate of the transported drug. Three levels of interactions may be distinguished, but all will involve surface phenomena between nanoparticle surface and compounds of the surrounding environment. Interactions occurring at the level of a mucosa may be critical to promote the absorption of the drug. They will be discussed in the first paragraph. The interactions taking place in the blood compartment which greatly affect the biodistribution of the carrier due to interactions with blood proteins are considered in the second paragraph. Finally, the more highly specific interactions between drug carrier and cells in the view of targeting and allowing delivery of the drug to very precise cells will be considered in the last paragraph of this section. As it will be discussed, carbohydrates appear, in all these cases, as versatile tools to control the interactions between the drug carriers and the biological surrounding media.

\subsection{Carbohydrates to improve mucoadhesion of nanoparticle drug carriers.}

Mucosal routes, especially the oral route, are the preferred methods for the administration of drugs. However, many drugs remain poorly available when they are administered by these routes. Among other reasons, this can be due to too low mucosal permeability for the drug, permeability restricted to a region of the gastrointestinal tract, low or very low solubility of the compound which results in low dissolution rate in the mucosal fluids and in elimination of a fraction of the drug from the alimentary canal prior to absorption, lack of stability in the gastrointestinal environment, resulting in a degradation of the compound prior to its absorption (e.g. peptides, oligonucleotides).

To reduce problems of low permeability and low solubility it was proposed to retain drug at the surface of the mucosa using bioadhesive formulations increasing the contact time between the drug and the epithelium and in turn chance to the drug to be absorbed. In this aim several authors have suggested to use polysaccharides to design bioadhesive nanoparticle drug delivery carriers. Chitosan obtained from deacetylation of chitin is the most commonly used bioadhesive polysaccharide. At the level of mucosa, chitosan is known to enhance drug absorption thanks to it bioadhesive properties and to its capacity to induce transient opening of the tight junctions without damaging the cells [63, 63]. Bioadhesive properties of chitosan were described for the first time by Lehr et al. [65]. They depend on the molecular weight $[66,67]$ and on the $\mathrm{pH}$ of the surrounded media which affect the polysaccharide solubility. Chitosan is soluble at pH below 6 and its bioadhesive properties require that the molecule is either soluble or strongly swollen |68]. Thus, to improve solubility properties of chitosan especially at $\mathrm{pH}$ higher than 6 encountered at the level of several mucosa, modified chitosans were synthesized. For instance, the partial substitution of the amino function of chitosan by methyl-5-pyrrolidone led to derivatives enhancing the absorption of drugs at the level of the bucal and vaginal mucosa [68-70]. Enhancement of the bioadhesive properties and of drug absorption was also reported after introduction of thiol groups in the structure of chitosan. In this case, the thiol groups are assumed to form disulfide bonds with the cystein rich domains of the mucus glycoproteins standing on the gastrointestinal mucosa [71, 72]. Drug carriers which have been coated with chitosan also showed enhanced bioadhesive properties at the level of different mucosa including the ocular, nasal, gastrointestinal, pulmonary mucosa [8,73-76]. However, it is worth to point out that a simple adsorption of chitosan at the nanoparticle surface is not enough stable to resist from desorption when the nanoparticles are in contact with the mucus [77]. Thus, several 
Author version from Vauthier et al., In "Handbook of Pharmaceutical Biotechnology", 2007. https://doi.org/10.1002/9780470117118.ch1d

authors have suggested to prepare nanoparticles directly with chitosan obtaining plain chitosan nanoparticles $[7,75]$ or to use copolymers of chitosan and the polymer constituting the nanoparticle i.e. poly(lactic acid) [61] or poly(alkylcyanoacrylate) $[19,21,62,78]$.

According to Prego et al. [8], the mucoadhesive properties of the carrier and its interaction with the mucus occurring in vivo are determinant to provide an efficient transport of the nanodevice carrying the drug across the epithelium resulting in increase of the bioavailability [8]. Mucoadhesive properties were shown to depend on the coating material but also on the size of the nanoparticles $[8,79]$. Generally, the smallest nanoparticles accumulate more because of a higher diffusion in the mucus layer compared to bigger particles. However, according to a very recent study, Bertholon et al. showed that the conformation of the chitosan chains grafted at the surface of poly(alkylcyanoacrylate) nanoparticles also influenced the bioadhesive properties of the nanoparticles on the intestinal mucosa [21]. Indeed, these authors reported differences in bioadhesion with nanoparticles onto which chitosan was grafted either on a "side-on" conformation or on the "end-on" conformation. Adhesion of the nanoparticles to the intestinal mucus layer can be viewed as a complex process, including the diffusion of the particles in the hydrogel, depending on their size, followed by their interactions with the mucus glycoproteins depending on both the nature of the polysaccharide and its conformation at the nanoparticle surface. It is likely that the molecular interactions played a key role in this latter process. Interestingly these results suggest that bioadhesive properties of nanoparticulate systems can be modulated by a fine tuning of the surface properties of the particles.

Several other polysaccharides were used to obtain bioadhesive formulations of drugs [80, 81]. Hyaluronic acid which is applied in ocular surgery to protect the corneal endothelium and to manipulate intraocular tissue is also a remarkable bioadhesive. It was suggested as coating material at the surface of nanoparticles made of poly(epsilon-caprolactone) for the development of bioadhesive ocular formulation of bioactive molecules to increase the retention of the drug at the level of the precorneal zone [82]. The other polysaccharides found in pharmaceutical formulations which may be interested to use as bioadhesive coated material at the surface of nanoparticle drug carriers are alginate, dextran, starch, cellulose derivatives including carboxymethylcellulose and hydroxypropyl cellulose. These polysaccharides have in common high swelling properties in aqueous environment.

\subsection{Use of carbohydrates to control the fate of drug carrier after intravenous administration.}

The fate of nanoparticles administered by the intravenous route is controlled by the interactions between the nanoparticle surface and serum proteins. In the blood, nanoparticles are normally considered as foreign bodies and are rapidly recognized as such by the host defence system. The primary event of the recognition phenomena is basically nonspecific and result in a massive adsorption of serum proteins at the nanoparticle surface [14, 59, 83]. Consequently, the complement system is activated leading to the labelling of the nanoparticle surface with specific activated proteins of the complement systems. Once the nanoparticles are labelled with activated complement proteins, they are efficiently recognized by macrophages of the mononuclear phagocyte system (MPS) due to the presence of the corresponding receptors at the cell surface. The overall process is so efficient that less than 5 minutes are generally necessary to remove from the blood 80 to $90 \%$ of the injected dose of the drug carrier. Following these events, the drug and its carrier are found in macrophages of the liver and of the spleen [9, 12, 84, 87]. This phenomenom is highly benefit to target drugs in the liver and spleen but hampered the distribution of the drug towards other biological territories.

Targeting territories, organs and tumors located outside the MPS organs can be achieved by triggering the host defence systems thanks to the modification of blood protein interactions with the nanoparticle surface in order to obtain long circulating nanoparticles. The more general approach 
Author version from Vauthier et al., In "Handbook of Pharmaceutical Biotechnology", 2007. https://doi.org/10.1002/9780470117118.ch1d

consists of grafting poly(ethylene glycol) chains at the nanoparticle surface to reduce both opsonization of the carrier surface by blood proteins and complement activation [14, 15, 59, 88]. An alternative route is based on a biomimetic approach using carbohydrates as material to coat the nanoparticle surface in order to modify interactions with blood proteins [19, 20, 31, 32, 89-92]. The design of biomimetic drug delivery systems using carbohydrate as surface coating material is almost infinite as much the diversity of carbohydrates appears to be in Mother Nature as exposed at the surface of the eukaryotic cells, bacteria, and viruses [5, 40, 44]. So far, only quite simple polysaccharides were used to modify surface properties of nanoparticle drug carriers. The simplest polysaccharide was dextran which is an alpha-1-6-poly(glucose). Measurements of complement activation given by different dextran-coated nanoparticles provided contradictory results depending on the method of the nanoparticle preparation. Indeed, dextran-coated poly(alkylcyanoacrylate) nanoparticles prepared by redox radical polymerization induced only a low complement activation $[19,20,31,32]$ while dextran-coated nanoparticles prepared by other methods induced a strong activation of complement so does sephadex which is a reticulated dextran [19, 20, 32, 90, 93, 94]. The contradictory complement activation measured could not be correlated to a marked difference in the interaction of the nanoparticles with blood proteins. Indeed, each type of the nanoparticles showed a proper pattern of blood protein absorption and no general behaviour could be drawn [32]. The hypothesis suggested to explain the results of complement activation is that it may depends on the conformation of the dextran chains at the nanoparticle surface which can be defined by the method of nanoparticle preparation. This hypothesis is supported by the results of a very recent work which showed that nanoparticles with dextran chains grafted at the nanoparticle surface on the "end-on" conformation are non activators when the molecular weight of dextran pass above a certain limit $(40000 \mathrm{~g} / \mathrm{mol})$ while the nanoparticles on which dextran are arranged on a "side-on" conformation activated complement whatever the molecular weight of dextran was [20]. The effect of the polysaccharide chain conformation was more evident with a series of chitosan-coated nanoparticles. Indeed, nanoparticles with chitosan on the "end-on" conformation were frankly non activators while the nanoparticles with chitosan on the "side-on" conformation were strong activators [20]. Although the conformation of the polysaccharide chains at the nanoparticle surface appeared to be a key parameter to control complement activation, several authors showed that the presence of dextran at the nanoparticle surface reduced the adsorption of albumin in favour of a reduction of opsonization phenomena [92, 95]. In term of biodistribution of the corresponding nanoparticles, the nanoparticles having dextran on the "side-on" conformation were recognized by macrophages of MPS and concentrated in the liver and in the spleen [13] while the nanoparticles with dextran on the "end-on" conformation remained in the blood circulation for a longer period [89].

Although chitosan coated nanoparticles showed contradictory results in complement activation depending on the conformation of the chains at the nanoparticle surface [20] the level of complement activation induced by chitosan was also influenced by the physico-chemical properties of the polysaccharide including its solubility, degree of deacetylation and molecular weight $[20,96-$ 98]. Using different chitosan and chitosan derivatives, nanoparticles with prolong circulation time in the blood can be obtained. Additionnaly, their distribution can be modulated in a certain way because they were found to accumulate in defined tissues outside the MPS [99- 104].

In Mother Nature, sialic acids play a key role of biological mask hiding epitopes at the cell surface which are immediately recognized by macrophages when the sialic acid is removed from the cell surface [103-107]. The most typical example is given by the erythrocytes which are rapidly destroyed when sialic acids are removed from their surface [106, 108, 109]. Highly virulent bacteria have also adopted sialic acids as coating material to escape host defence mechanisms [110-112]. Sialic acids which seem to inhibit complement activation allow cells and particular material to stay in the blood without being recognised by macrophages [110]. Thus, it was suggested to coat nanoparticles with sialic acids to mask their surface and avoid recognition by macrophages. Two different approaches 
Author version from Vauthier et al., In "Handbook of Pharmaceutical Biotechnology", 2007. https://doi.org/10.1002/9780470117118.ch1d

were followed. At first, the adsorption of a sialic acid rich glycoprotein, orosomucoid, at the surface of poly(alkylcyanoacrylate) nanoparticles reduced opsonization of the nanoparticles and complement activation. However, the orosomucoide which was simply adsorbed at the nanoparticle surface was rapidly displaced from the surface by other serum proteins due to the Vroman effect and the effect of the sialic acids could be shown on short duration $[17,113]$. Second, the nanoparticles coated with sialic acid were obtained from a copolymer of poly(sialic acid) and poly(lactic acid). These nanoparticles coated with a polysialic acid remained in the blood circulation longer than the uncoated nanoparticles after intravenous administration to mice [114]. Poly(sialic acids) have the advantage of being biodegradable and their catabolic products (e.i. neuraminic acids) are not known to be toxic. Another important advantage of poly(sialic acids) is their T-independent antigens meaning that they do not induce immunological memory. Because of these properties, poly(sialic acids) are very promising molecules to design biomimetic drug carrier systems with an increase half life in the blood stream of drug carrier $[16,115]$. The main limitation of the development of such drug carriers so far may be explained by the poor availability of poly(sialic acids) which remained a problem because they are produced by highly pathogenic bacteria strengths at a very high cost.

The other bioactive polysaccharide which appeared interesting to be used to produce surface modified nanoparticles reducing their recognition by the host defence was heparin. Heparin is used as a drug for its anticoagulation properties. Additionally, it is an inhibitor of the complement activation phenomenon [116-118]. It was demonstrated that heparin coated nanoparticles did not activate the complement system [19, 31,32] and remained in the blood stream for longer time compared to nanoparticles which do not show heparin on the nanoparticle surface [89]. Other polysaccharides extracted from mushrooms were found to inhibit the activation process of complement. They could be alternative polysaccharides to produce nanoparticles with reduced capacity to activate complement so does heparin [119].

According to the current experiences, several polysaccharides can be used to modulate the interactions of nanoparticle drug carriers with blood proteins modifying their blood clearance and consequently their biodistribution. Two categories of polysaccharides giving nanoparticles able to escape recognition from macrophages of the SPM can be identified. The first category including heparin and sialic acids are specifically interacting with serum protein according to a well-defined mechanism thanks to their specific biological activity being inhibitors of the complement activation phenomenom. The polysaccharide of the other category including dextran would interact with serum protein through nonspecific interactions. In addition to the specific and non-specific interactions with blood proteins, it was clearly demonstrated that the conformation of the chains grafted at the nanoparticle surface is one of the key parameters which control the complement activation phenomena and the opsonization of the nanoparticle surface. The nature of the polysaccharide and the molecular weight appeared at the second level of importance [20].

\subsection{Carbohydrates and drug carrier targeting perspectives.}

Colloidal carriers have proved their interest to deliver drugs by the intravenous route because of their potential to improve therapeutic index of the carried drug while reducing their side effects. Although with the current systems available it can be possible to enhanced accumulation of the drug in diseased tissue especially in tumors, the interactions of the carriers with diseased cells and their uptake remain insufficient. The main strategy which was proposed to further enhanced drug delivery and retention at the level of diseased cells is based on the active targeting of the drug [12, 120-122]. This supposes that drugs reached target cells thanks to a highly specific biodistribution of the carrier. Our experience with drug carriers suggests that such a degree of specificity will only be obtained if the drug carrier can recognize the target cells through very specific interactions.

One way to promote recognition between drug carriers and target cells is to attach ligands at the carrier surface being able to bind specifically to target cells $[12,121,122]$. In this purpose, more or 
Author version from Vauthier et al., In "Handbook of Pharmaceutical Biotechnology", 2007. https://doi.org/10.1002/9780470117118.ch1d

less complex carbohydrates can be used as ligands of endogenous receptors for carbohydrates known as lectins at the cell surfaces. Lectines are universally found in the microbial world, on vegetal and animal cells $[5,28,123]$. They can bind various types of carbohydrates from simple monosaccharides to oligo or polysaccharides of complex structures with a very high specificity of recognition resulting in strong interactions. The binding is a very fast process and the recognition between the carbohydrate and the corresponding lectin can occur whether the carbohydrate is free or bound on a macromolecule or on the surface of cells and of drug carriers [123, 124]. So far, most of the work done in the field of active targeting was performed with liposomes and soluble polymers. At present, only few studies were carried out on nanoparticles [12, 121, 125]. Microbial and vegetal lectins were bound to drug carriers as targeting moiety to find complementary carbohydrate epitopes at the surface of target cells [126-128]. However, with the recent progress in glycobiology, it seems that a better option would consist in grafting the carbohydrates on the drug carrier instead of lectins which often loose activity during the grafting process. Another advantage of using carbohydrates as the targeting moieties is that the drug carrier would be targeted towards cell receptors which expression levels are subjected to dramatic modifications upon physiological conditions of the cells. For instance, in several cancer cells, some receptors are specifically overexpressed while other are down regulated and almost disappear from the cell surface. Thus, it seems better to use the ligand receptor, i.e., carbohydrate, as the targeted moiety attached on the drug carrier to take advantage of differences in the level of receptor expression in the targeting strategy. This method which was applied with folic acid actually showed high targeting potential [129]. Additionally, it would probably be easier to find quite universal methods for grafting various types of carbohydrate moiety on nanoparticle surface in comparison with the coupling methods of proteins which needs to be finely adjusted for each protein receptor to preserve the functionality of their active site [44].

Many endogenous lectins in animals might serve as targets receptors for drug carriers exhibited complementary carbohydrates at the surface. Examples of animal lectins and principal characteristics, locations and specificities are given in table 1 while table 2 summarizes variations of the level of expression of lectins in several diseases that were already identified and reported in the literature.

This last table may be especially useful to identify over-expressed lectins on diseased cells and which may be used as target to direct drug delivery carriers bearing the corresponding carbohydrate ligand specifically toward them. Such a targeting strategy was successful using soluble drug carriers [126, $137,141,142]$, and in the case of targeting DNA/polymer complexes [130, 143-147] bearing simple carbohydrate or polysaccharides. Most of the work done so far with nanoparticles included monoand di-saccharides as the targeting moiety. Lectins can recognize galactose and mannose residues after chemical grafting at the surface of polymer nanoparticles [148, 149]. Galactose was used to target paclitaxel-loaded nanoparticles towards hepatic cells. The lectins of the hepatic cells specifically recognised the galactose residues at the surface of the nanoparticles improving the targeting of the drug in these cells. Thus, the nanoparticles were found more toxic towards the cells expressing the lectin at the surface compared with cells devoid of the corresponding lectin [150]. It also seems that lactose bearing nanoparticles being recognized by asialoglycoprotein receptors of hepatic cells of mice are internalized by endocytosis [151]. A carbohydrate of Lewis was suggested as targeting moiety to target poly(lactide-co-glycolide) nanoparticles towards cells expressing $\mathrm{E}$ selectins on endothelial cells or in inflammatory sites. It was found that, for this more complex carbohydrate corresponding to an oligosaccharide, the affinity of the E-selectins for the Lewis carbohydrate exposed at the nanoparticle surface depended on the density of grafting [121]. 
Table 1. Principal characteristics of some animal lectins.

\begin{tabular}{|c|c|c|c|c|c|c|}
\hline Class & Subclass & General properties & Localization & Specific ligand & $\begin{array}{l}\text { Non-specific } \\
\text { Ligand }\end{array}$ & Ref. \\
\hline \multirow{4}{*}{ 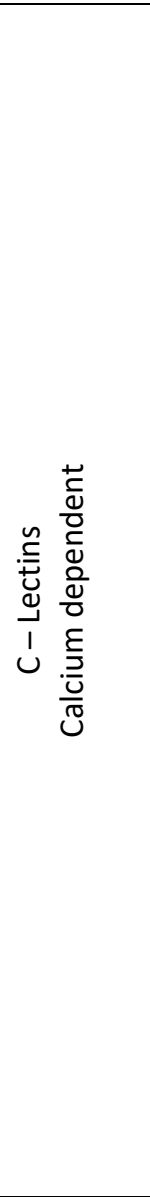 } & $\begin{array}{l}\text { Endocytic } \\
\text { receptors }\end{array}$ & $\begin{array}{l}\text { Asialoglycoprotein receptors } \\
\text { Involved in the clearance of } \\
\text { desialylated proteins }\end{array}$ & $\begin{array}{l}\text { Hepatocyte } \\
\text { Liver endothelial cells } \\
\text { Kuppfer cells } \\
\text { Macrophages } \\
\text { Parenchymal liver cells } \\
\text { Non parenchymal liver cells }\end{array}$ & $\begin{array}{l}\text { Ending } \beta \text { D galactose } \\
\text { Ending N Acetylgalactosamine } \\
\text { Ending N Acetylgalactosamine } \\
\text { Ending N Acetylgalactosamine } \\
\text { Mannose } \\
\text { Arabinogalactane } \\
\text { Ending Galactose } \\
\text { Pullulan } \\
\text { Manan }\end{array}$ & $\begin{array}{l}\text { Dextran } \\
\text { Dextran } \\
\text { Pullulan } \\
\text { Arabinogalactan } \\
\end{array}$ & $\begin{array}{l}{[120,130]} \\
{[131,132]} \\
{[133]}\end{array}$ \\
\hline & Selectins & $\begin{array}{l}\text { Transmembrane glycoproteins } \\
\text { involved in cell traffic to injury } \\
\text { and inflammation sites }\end{array}$ & $\begin{array}{l}\text { Platelets ( } P \text { selectin) + endothelial } \\
\text { cells } \\
\text { Endothelial cells (E selectin) } \\
\text { Leukocyte (L selectin) }\end{array}$ & $\begin{array}{l}\text { Heparin } \\
\text { Sulfated and sialylated ligands } \\
\text { Heparin }\end{array}$ & & \begin{tabular}{|l}
{$[121,125]$} \\
{$[121,125,134]$} \\
{$[132,134]$}
\end{tabular} \\
\hline & Collectins & $\begin{array}{l}\text { Involved in innate immune } \\
\text { phenomena }\end{array}$ & & $\begin{array}{l}\begin{array}{l}\text { Saccharides on pathogens or } \\
\text { allergens }\end{array} \\
\end{array}$ & & [132] \\
\hline & Proteoglycans & $\begin{array}{l}\text { Involved in regulation } \\
\text { mechanisms of cell growth, } \\
\text { differentiation and lipid } \\
\text { metabolism. }\end{array}$ & \begin{tabular}{|l} 
Hyaluronate receptor: \\
CD44: hematopoietic cells \\
Fibroblast \\
RHAMM: Fibroblast \\
Smooth muscular cells \\
Macrophages \\
Lymphocytes \\
ICMA 1: Leukocytes \\
Macrophages \\
Non hyaluronate receptors: \\
\end{tabular} & $\begin{array}{l}\text { Hyaluronic acid and sodium salts } \\
\text { Fructose, Galactose } \\
\end{array}$ & & $\begin{array}{l}{[135-138]} \\
{[139]} \\
{[132]} \\
\end{array}$ \\
\hline \multirow{2}{*}{ 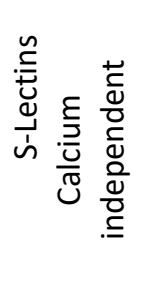 } & Galectins 1 & $\begin{array}{l}\text { Cell adhesion and proliferation, } \\
\text { regulation of immune } \\
\text { infections }\end{array}$ & Skeletal muscle & $\begin{array}{l}\text { B Galactoside } \\
\text { Glucose }\end{array}$ & & {$[132,140]$} \\
\hline & Galectins 3 & Allergy, inflammatory process & \begin{tabular}{|l|} 
Eosinophils \\
Neutrophils \\
Macrophages \\
Epithelial cells \\
\end{tabular} & $\begin{array}{l}\beta \text { Galactoside } \\
\text { Glucose }\end{array}$ & & [132-140] \\
\hline
\end{tabular}


Author version from Vauthier et al., In "Handbook of Pharmaceutical Biotechnology", 2007. https://doi.org/10.1002/9780470117118.ch1d

Table 2: Modification of expression level of different lectins in several pathologies

\begin{tabular}{|c|c|c|c|}
\hline Pathologies & Over-expressed lectins & $\begin{array}{l}\text { Under-expressed } \\
\text { lectins }\end{array}$ & Ref. \\
\hline Cancer & $\begin{array}{l}\text { P Selectins in plasma } \\
\text { Hyaluronate receptor CD44 } \\
\text { and RHAMM } \\
\text { Galectins }\end{array}$ & & $\begin{array}{l}{[121,125,140} \\
]\end{array}$ \\
\hline Metastasis & $\begin{array}{l}\text { E Selectins } \\
\text { Hyaluronate receptor CD44 } \\
\text { and RHAMM }\end{array}$ & & $\begin{array}{l}{[132]} \\
{[135-138]}\end{array}$ \\
\hline Colon cancer & Galectins 1 et 3 & Galectin 8 & \\
\hline Meningeal leukaemia & L Selectins & & |126] \\
\hline Malignant B-cells & L Selectins & & $\begin{array}{l}{[121]} \\
{[121]}\end{array}$ \\
\hline Angiogenesis & E Selectins & & [132] \\
\hline Connective tissue disease & P Selectins in plasma & & {$[121,125]$} \\
\hline Rheumatoid arthritis & $\begin{array}{l}\text { P Selectins in plasma } \\
\text { E Selectins }\end{array}$ & & {$[121,125]$} \\
\hline Asthma, allergy & $\begin{array}{l}\text { P Selectins in plasma } \\
\text { E Selectins }\end{array}$ & L Selectins & {$[121,125]$} \\
\hline Multiple sclerosis & L Selectins & & [121] \\
\hline Kawasaki disease & E Selectins & L Selectins & [121] \\
\hline Guillain - Barre syndrome & E Selectins & & {$[121]$} \\
\hline Intestine disease & P Selectins in plasma & & {$[121,125]$} \\
\hline Sever infection (malaria) & $\begin{array}{l}\text { P Selectins in plasma } \\
\text { E Selectins }\end{array}$ & & {$[121,125]$} \\
\hline Neonatal bacterial infection & & L Selectins & [121] \\
\hline & L Selectins & & [121] \\
\hline Insulin-dependent diabetes & L Selectins & & [121] \\
\hline Risk factors of stroke & & L Selectins & [121] \\
\hline $\begin{array}{l}\text { Cardiopulmonary bypass } \\
\text { surgery }\end{array}$ & & L Selectins & [121] \\
\hline
\end{tabular}

According to these data, targeting strategies which involve carbohydrates are principally directed towards cell receptors involved in mechanisms of cell regulation and communication either between cells or with the surrounding medium. They are based on very specific interactions with high affinity between the ligand and the corresponding receptor. So far, they have been applied with quite simple carbohydrates including monosaccharides, di-saccharides and some Lewis carbohydrates. It provided more than satisfactory results regarding the level of targeting specificity as evaluated in vitro using relevant cell models. Only few studies which went over the in-vitro stage were performed with liposomes and soluble drug carriers providing extremely convincing perspectives [122, 141, 152]. There is no doubt that similar targeting efficiency may be obtained with success using nanoparticles. It can also be expected that current investigations aiming to identify structures and biological functionalities of carbohydrates at a large scale will contribute amplifying our knowledge in cell communication and therefore highlighting new targets and targeting carbohydrate-based materials $[5,35,40,44,153]$. This promises very exiting developments in the future. However, as stressed by Nobs et al, one has to keep in mind that the ability to achieve targeting in vivo depends directly on whether or not the target is accessible from the vascular compartment [12]. In the first case, 
Author version from Vauthier et al., In "Handbook of Pharmaceutical Biotechnology", 2007. https://doi.org/10.1002/9780470117118.ch1d

particles bearing targeting moiety and having long circulating properties have a high probability to reach the target cells. On the contrary, when the target is extravascular, for instance in solid tumors, penetration of the carrier in the tumor tissue is more difficult because it needs to extravasate. In this case, the size of carriers needs also to be adjusted so that they can cross the vessel endothelial through the pores of the local discontinuous tumor microvasculature which may vary between 100 to $780 \mathrm{~nm}$. Another requirement would probably concern the orientation of the carbohydrate moiety at the nanoparticle surface. Indeed, biological recognition systems are so sensitive that they are, for example, capable to differentiate small changes in conformation of epitopes at the surface of pathogens.

\section{ENHANCEMENT OF CARBOHYDRATE THERAPEUTIC ACTIVITY BY ASSOCIATION WITH NANOPARTICLE DELIVERY SYSTEMS.}

Research to understand biological functions of carbohydrates are currently extremely active providing new data almost everyday. The literature is growing exponentially in this very fast-moving area. The purpose of this chapter was not to review all the different biological activity known for carbohydrates today but was to focus on carbohydrates which biological activity are interesting for therapeutic purpose and whose therapeutic efficacy may be improved by association with a nanoparticle drug carrier.

\subsection{Anti-infectious agents}

The emergence of antibiotic resistant strengths of bacteria, parasites, fungus viruses and new pathogens are very demanding for the discovery of new anti-infectious agents. If the discovery of new molecules is undoubtedly the leading strategy in finding effective treatments, all active molecules will need to reach sites of infections where pathogens are located at sufficient concentration. Several efficient carbohydrate antibiotics were extracted from various strengths of Streptomyces. They are quite simple aminoglycoside molecules known as streptomycins including neomycin, gentamicin, or amikacin. Other recently discovered carbohydrate antibiotics including the family of the orthosomycins are more complex molecules. These carbohydrate antibiotics are very attractive because they are efficient against pathogen bacteria including those resistant to antibiotics used in last resort (penicillin or vancomycin). Their interest is so huge that several methods for their synthesis were already suggested [154-156]. However, they are generally very toxic for healthy tissues limiting the maximal dose of antibiotic which can be administered in patients and consequently the efficacy of treatment. In general, the efficacy of antibiotics can be considerably increased when they are associated with drug carriers thanks to a reduction of the toxicity and a higher accumulation in the infected cells which, in many infections, are cells of the mononuclear phagocytes system. The improvement of the safety profile of the targeted drug allowed administration of higher doses of the antibiotic when requested to promote treatment efficacy [48, 157]. In other cases, the therapeutic index of the antibiotic was markedly increased by factor ranging from 6 to up to 120, thus, the dose of antibiotic required to kill infectious agents can be considerably reduced [158-164]. Complete sterilization of organs could be obtained with the antibiotic targeted with nanoparticles while the corresponding liposomal formulation could not completely sterilize the organs in the same experimental condition [165].

Currently, there is only one formulation of Amikacin in liposomes under clinical trials for treatment of tuberculosis. The antibiotic was found 2 to 6 -fold more active than the free drug in an acute experimental model of murine tuberculosis in which bacteria are located in macrophages. The count of viable bacteria found in the liver and spleen was reduced by a factor of 3- $\log _{10}$ compared with the untreated mice [158]. However, in human, this formulation was not as active as expected. To explain 
the disappointed results obtained, it was suggested that the liposomes could target the antibiotics in the macrophages, but this was not enough to reach extracellular bacilli which are clustered in cavity caseum in the human infection and can be responsible for reinfection. It was suggested that these residual bacteria may be reached using drug carriers with long-circulating properties.

So far, the more advanced studies on the targeting of antibiotics which reach the clinic stages were performed with liposomes. The only formulation marketed so far, Ambisome ${ }^{\circ}$, is the more efficient treatment against leishmaniasis and other fungal infections [47]. This demonstrates the high potential of targeted formulations of antibiotics to challenge devastating pathogens with rather toxic antibiotics for healthy tissue provided that they are targeted to the infected cells. It may be expected that research will continue considering targeting strategies of the most interesting carbohydrate antibiotics to improve the efficacy of anti-infectious treatments. In this view, it will also be interesting to pay attention to nanoparticle formulations which appeared more efficient than liposomes when they were tested in same conditions probably because of their higher stability in the blood compartment in vivo $[157,161]$.

Some polysaccharides showed either antibacterial and anti-fungal activities or antiviral activity. For instance, the anti-bacterial and anti-fungal activity of chitosan was studied for a long time both in vitro and in vivo. They are used to control bacterial infections during wound healing process [166]. The activity of chitosan against pathogens is maximal at acidic pH [166, 167]. The degree of acetylation has no influence on the activity but high molecular weight chitosans were reported to be active against the Gram-negative bacteria Escherichia coli [169]. Depending on the authors, either high or low molecular weight chitosan were reported to be active on the Gram-positive bacteria Staphylococcus aureus $[168,169]$. To explain activity of chitosan, it is assumed that high molecular weight chitosan may form a film around the bacterial preventing the exchange of nutriment while low molecular weight chitosan may enter bacteria cells to disturb metabolism [169]. Other mechanisms were suggested such as chelation of metal ions required for the synthesis of the bacterial toxin or interaction with cell membrane components inducing agglutination of bacteria or increasing of the permeability of the cell membrane $[167,170]$. Chemically modified derivatives of chitosan such as diethy-methyl chitosane are more active than chitosan [171]. Chitosan has not yet been used in a targeted formulation for in vivo application. However, it was associated at the surface of nanoparticles to obtain fabrics with antibacterial activity.

Finally, antiviral activities were reported for polysaccharides bearing sulfonate groups. Most of the studies considered either the activity against the human herpes virus simplex 1 and 2 or against the Human Immunodeficiency Virus (HIV). Generally, the antiviral activity depended on the molecular weight, the amount and the distribution of the sulfonate groups, the conformation and flexibility of the polysaccharide chains [172]. It was suggested that the anti-HIV activity can result from electrostatic interactions occurring between the negatively charged sulfonate groups of the polysaccharide and the positively charged amino groups of the glycoprotein GP120 of the virus envelope [173]. Polysaccharides with antiviral activity can be obtained by grafting sulfonate or sulfamide groups [172, 174]. Modified dextranes containing carboxymethyl benzylamine and carboxylmethyl benzylaline sulfonates groups showed anti-HIV activity [175] while the anti-herpes virus activity was described for carraghennan corresponding to sulfated polygalactanes extracted from a red alga [172]. More interestingly, a sulphated polysaccharide extracted from the algae Caulerpa racemosa is active against strengths of the herpes virus resistant towards acyclovir which is one of the leading antiviral compounds used in clinics [176]. All these polysaccharides showing antiviral activity may be interesting compounds to target against infected cells. 
Author version from Vauthier et al., In "Handbook of Pharmaceutical Biotechnology", 2007. https://doi.org/10.1002/9780470117118.ch1d

\subsection{Anticancer activity}

Several small carbohydrates derivatives showed anticancer activity and are used in clinics as antitumoral drugs [33-35]. Pharmacologically active concentrations of such an anticancer drug in the tumor tissue are often reached at the expense of massive contamination of the rest of the body. As it was discussed above with antibiotics, this poor specificity creates a toxicological problem that represents a serious obstacle to effective anti-tumor therapy. Another obstacle to their efficient delivery is the occurrence of multidrug resistance (MDR) which may appear either as a lack of tumor size reduction or as a clinical relapse after an initial positive response to the tumor tissue, it can be either directly linked to specific mechanisms developed by the tumor cells or it can be connected to the physiology of the tumor tissue, including a poor vasculature and unsuitable physicochemical conditions [177]. Outside the tumor tissue, the resistance to chemotherapy can be due to the more general problem of the distribution of a drug relative to its targeted tissue [15]. To overcome drug resistance many attempts have been made using strategies that consider the more general problem of the control of the drug biodistribution either at the cellular level or at the tissue level $[178,179]$. All these reasons make small carbohydrate anti-tumoral drugs relevant candidates to be formulated in drug delivery systems allowing their targeting in tumors as it was already demonstrated with the anthracyclin doxorubicin [50, 180-183].

Antitumor activity was reported for several polysaccharides too [35]. Nanoparticles made of chitosan either loaded with copper or unloaded showed a higher cytotoxicity against tumoral cells while their cytotoxicity remained low towards healthy cells of human liver L-02. The antitumoral efficacy depended on the nanoparticle diameter being the highest with the smaller nanoparticles $(40 \mathrm{~nm})$ [184]. Heparin showed interesting antitumoral activity especially when it formed complex with poly(beta-aminoesters), a positively charged polymer, which enhanced the intracellular penetration of heparin by endocytosis into cancer cells. The mechanism of the anticancer activity of heparin was explained by an induction of apoptosis in cells in which the polysaccharide was internalized. The specificity of the activity against cancer cells was explained by a favourable competition of the endocytosis towards these cells compared to the lower endocytosis activity of healthy cells. However, it may be suggested that the specificity of the delivery may further be increased by a specific delivery of the conjugate at the level of the tumor $[185,186]$. Many other carbohydrates and polysaccharides have recently been isolated showing antitumoral activity. The characterization of their structure and mechanism of action are still not fully elucidated and this is part of a very active field of investigation. Among the very recently isolated compounds showing an antitumoral activity, several were extracted from plants, mushrooms and microorganisms [143, 187-191] or were collected from their culture medium [192]. It was shown that some of the extracted polysaccharides may interact with the host defence mechanisms to induce a production of interleukin- 2 which in turn can stimulate either cytotoxic T lymphocytes, Natural Killer lymphocytes or production of antibody against tumoral cells [187]. Other hypothesis suggested that the polysaccharides are able to stimulate macrophages resulted in a production of nitrogen oxide, NO, and of tumor necrosis factoralpha (TNF- $\alpha)[143,188,192-194]$. A direct activity against tumoral cells was also assumed [188, 189]. Finally, certain of the active compounds may act on the angiogenesis reducing the formation of neovessels required for the irrigation of the tumor tissue [190, 191].

\subsection{Control of vascular smooth muscle cell proliferation}

Several sulfonated polysaccharides showed ability to control proliferation of vascular smooth muscle cells. Certain compounds may act on the angiogenesis reducing the formation of neo-vessels required for the irrigation of tumor tissues [190, 191]. They can contribute to reduce tumor size growth. Other can inhibit the proliferation of the vascular smooth muscle cells on damaged artery to prevent and control artherosclerosis [195]. The inhibitor activity of the polysaccharides seemed to 
Author version from Vauthier et al., In "Handbook of Pharmaceutical Biotechnology", 2007. https://doi.org/10.1002/9780470117118.ch1d

increase with their molecular weight because it is assumed that they are better internalized by cells. Among sulfonated polysaccharide, fucan showed a higher activity compared to heparin [196, 197]. With modified dextran, the inhibition of cell growth depended on the degree of substitution by sulfonate groups and on the presence of benzylamide groups. The production of collagen by the vascular smooth muscle cells was influenced by modified dextran and heparin [198]. Complexes between sulfonated polysaccharides such as heparin, hyaluronate and chondroitine sulphate with chitosan were also reported to control proliferation of vascular smooth muscle cells [199].

Sulfonated polysaccharides present different biological activities. To take advantage of their antiproliferative activity towards vascular smooth muscle cells, it will be necessary to associate the polysaccharides with targeted drug carriers such as nanoparticles. The nanoparticles may also enhance the cellular endocytosis of the polysaccharides to further promote its anti-proliferative activity on vascular cells.

\subsection{Activity on the immune system}

Many of the antigens located at the surface of pathogens show more or less complex carbohydrate epitopes. The immune response induced by these antigens results in the production of antibodies which is relevant in the aim of vaccination [200-203]. Thus a few vaccines were developed using polysaccharide antigens against meningitis [203, 204], pneumonia [202] and against Staphylococcus aureus which is responsible for nocosomial infections [201]. Usually, an efficient vaccine requires formulation of the antigen with adjuvant. The more recent formulation strategy which was followed for vaccine development was based on the design of antigen presenting devices using nanotechnology [205-207]. Systems proposed so far on the one hand, derived from the liposome technology based on phospholipid bilayer reconstitution with incorporation of antigenic protein or glycoprotein i.e., virosomes $[205,206]$ and, from the other hand, on the reconstitution of empty viral capside with viral recombinant proteins i.e., virus like particles [207]. Finally, the immune stimulating complex (ISCOM) corresponds to a nanosized aggregate (40 $\mathrm{nm}$ in diameter) of saponin, lipids and antigen held together by hydrophobic interactions occurring between the three components [208]. All these systems formed spontaneously upon self molecular assembly mechanisms. They were mainly developed as vaccines against viral infections and are mimicking viruses showing the corresponding antigenic epitopes at the surface. Although they are efficient for parenteral vaccinations, their application in mucosal vaccines is subjected to controversy because of possible stability problems in the biological environment of mucosa. Thus, there is a need for development of antigen presenting systems for bacterial antigens including those of polysaccharide nature and for antigen presenting devices stable enough in biological media encountered at the level of mucosa to develop mucosal vaccination. Several types of polymer nanoparticles were proposed as carriers for antigens to be used as vaccine adjuvants $[209,210]$. In general, in these systems, the antigen is mostly encapsulated within the nanoparticles and is not "visible" from the outside of the carrier as it is the case of systems obtained by self assembly molecules i.e., in virosomes and virus like particles. Polysaccharide-coated nanoparticles would be more suitable as possible antigen presenting devices. To this purpose, nanoparticles were specifically designed to exhibit polysaccharide at the nanoparticle surface and can easily be obtained with various polysaccharides [211]. Its versatility should offer interesting developments for new vaccines as polysaccharide antigen presenting device.

Although carbohydrate antigens were first described a long time ago, their interactions with the immune system are not limited to the production of antibodies in the frame of vaccination. Indeed, some polysaccharide can modulate the immune system activity in a very specific manner. For instance, several polysaccharides interact with interleukin 10 (IL-10) [212]. Human IL-10 is known to stimulated CD16 and CD64 receptor expression on the monocyte and macrophage population within peripheral blood mononuclear cells. Soluble heparin, heparan sulfate, chondroitin sulfate, and 
Author version from Vauthier et al., In "Handbook of Pharmaceutical Biotechnology", 2007. https://doi.org/10.1002/9780470117118.ch1d

dermatan sulfate inhibit the human IL-10-induced expression of CD16 and CD64 in a concentrationdependent manner. The antagonistic effect of heparin on human IL-10 activity depends on Nsulfation, the de-N-sulfated heparin had little or no inhibitory effect on the IL-10- induced expression of $C D 16$, whereas the effect of de-O-sulfated heparin was comparable to that of unmodified heparin. Furthermore, the inhibition of cell-bound proteoglycan sulfation reduced the human IL-10-mediated expression of CD16 molecules on monocytes and macrophages. Taken together, these findings support the hypothesis that soluble and cell-surface glucosaminoglycans, and their sulfate groups in particular, are important in binding and modulation of human IL-10 activity and therefore to promote or inhibit several pathways of the immune system. It may be suggested that these molecules grafted at the surface of a polymer nanoparticles may regulate the expression of the receptors at the cell surface modifying the immune system response in a very define and precise manner.

Small oligosaccharides are able to inhibit immune response by reducing production of oxidative species in immune cells. These components may be interested to control inflammatory process and for treatment of auto-immune diseases. Activity depended on both length and conformation of the oligosaccharides. It seemed that oligosaccharides longer than 6 residues and adopting a helical conformation enhanced interaction with immune system components [213]. The immunomodulation properties shown by such oligosaccharides can be combined with anti-inflammatory properties of other polysaccharides extracted from Costus spicatus [214]. Although several oligosaccharides are able to inhibit immune response, others stimulate the immune system. Polysaccharides extracted from Lycium barabrum promoted expression of IL-2, TNF-alpha in the peripheral mononuclear cells in human [215]. Those extracted from Discirea opposita induced proliferation of T lymphocytes [216]. It was suggested that stimulation of macrophages resulted from an interaction occurring between the n-acetylglucosamine groups of the oligosaccharides with the mannose calcium-independent receptors of the macrophages $[217,218]$.

Presenting under the form of nanoparticles, these polysaccharides may be better targeted towards macrophages and monocytes to focus activity of the polysaccharide in macrophages and to avoid reaching other cells which may be affected by unspecific action on metabolism or physiology. Indeed, it will be very important to precisely target polysaccharides like heparin because it has other biological activity. The various activities found for polysaccharides on the immune system may be used to finely tune the activity of the very complex defense system of the host. This could let to the emergence of new therapeutic strategies providing the polysaccharides or the oligosaccharides will be precisely targeted against the right cells of the immune systems.

\subsection{Control of blood coagulation and complement activation}

Polysaccharides and oligosaccharides may induce or inhibit blood coagulation depending on their structure. Chitosan and polysaccharides extracted from the Chinese laquer showed biological activity promoting the blood coagulation $[173,119]$. In general, negatively charged polysaccharides including sulphate, sulfonate, carboxylic and sulphonamide groups show opposite activity having anticoagulant properties. Heparin which is used in clinics and for storage of blood in the blood banks is for sure the more generally known natural anticoagulant agent $[134,220]$. For the other polysaccharides including sulphated and carboxylated derivatives of dextran, galactomannan, pullulan and chitosan, it was shown that the amount of functional groups, their distribution along the chain and the molecular weight of the polysaccharide chains are all parameters which influence the anticoagulant activity of the polysaccharide [174, 220-226]. In clinics, the main problem encountered with treatments based on the use of heparin is the rapid elimination of the polysaccharides from the blood stream. Long circulating formulations of heparin with longer biological and therapeutic efficacy may consist of heparin associated with long circulating drug carriers. It was reported that some nanoparticles coated with heparin displayed long circulating properties and that the anticoagulant 
Author version from Vauthier et al., In "Handbook of Pharmaceutical Biotechnology", 2007. https://doi.org/10.1002/9780470117118.ch1d

activity of the heparin was preserved after grafting on the nanoparticle surface making these nanoparticles interesting as potential long-acting anticoagulant agent $[19,89]$. Heparin which is used in clinics must be administered via the parenteral route which is expensive, inconvenient, unsafe, and limits use by outpatients. The development of an oral form of heparin is more than warranted because the oral route remains the preferable route of administration of drugs for patient. It is also the safer and less expensive route for the administration of drugs so far. However, heparin is a polyanionic macromolecule and is unstable under acidic conditions of the stomach thus exhibiting poor oral bioavailability [227]. Nanoparticles were found to enhance absorption of hydrophilic macromolecules across the intestinal epithelium [51]. They appeared as interesting alternative for the development of an oral formulation of heparin to promote its bioavailability by this challenging route of administration.

\section{NANOPARTICLE DRUG CARRIERS MADE OF CARBOHYDRATES FOR THE DELIVERY OF FRAGILE MOLECULES}

Among the different delivery approaches explored so far to deliver complex molecules such as peptides, proteins, and nucleic acids by mucosal routes, those based on the use of polysaccharide nanoparticles were found interesting alternatives towards this ambitious goal thanks to physicochemical and biopharmaceutical properties of these polymers [6-8, 51]. Indeed, the mucosal delivery of these molecules is very challenging and despite their increasing market value, their clinical use was hampered due to their poor natural transport across biological barriers and their extremely rapid degradation in biological media. Elaboration of the polysaccharide nanoparticles requires neither organic solvent nor powerful homogenization procedure possibly damaging macromolecular drug activity [75, 228]. This is an advantage regarding all the other preparation methods of nanoparticles. Indeed, the mild conditions used preparing polysaccharide nanoparticles suits with those required to preserve biological activity of peptides, proteins, and nucleic acids in the nanoparticle formulations [9]. So far, nanoparticles made of chitosan have opened promising alternatives for the delivery of peptides, proteins and nucleic acids by the mucosal route including oral and nasal administration and for topical delivery of drugs in the eye [229-231]. The system which is stable in mucosal environment including in the harsh conditions of the gastrointestinal tract can interact with the negatively charged glycoproteins of the mucus which cover the epithelium retaining the nanoparticles on the mucosa surface. This retention effect due to bioadhesive properties of chitosan to mucus increases chance for the drug to be absorbed. The drug loaded nanoparticles either made of chitosan or bearing a chitosan coating enhanced drug penetration and absorption after administration by different mucosal routes. For instance, the oral absorption of salmon calcitonin was improved when it was associated with chitosan nanoparticles. Interestingly, this system elicited long-lasting hypocalcemia levels, whereas a calcitonin emulsion used as control led only to a negligible response [8]. To explain the effect, it was suggested that the nanosystems were able to enter the epithelia and provided a continuous delivery of the peptide to the blood stream [8, $232,233]$. Insulin-loaded chitosan nanoparticles also improved the delivery of insulin by the nasal route [234]. This formulation may be interested in applications requiring a rapid supply of insulin in the blood. Indeed, the hormone is absorbed in about $30 \mathrm{~min}$, but the duration of the effect was quite short, lasting for 1.5 to 2 hours.

Chitosan nanoparticles as well as chitosan-coated nanoparticles were also found interesting for the delivery of antigens to the Nasal Associated Lymphoid tissue. The results indicated that the nanoparticles were able to facilitate the transport of the associated antigen across the nasal epithelium leading to an efficient antigen presentation to the immune system. This elicited both an $\operatorname{IgA}$ and IgG response increasing over time. For the immune response, it was suggested that not only the size and surface properties of the nanoparticles may influence the immune response but also the 
Author version from Vauthier et al., In "Handbook of Pharmaceutical Biotechnology", 2007. https://doi.org/10.1002/9780470117118.ch1d

polymer composition and the structural architecture of the nanosystems which were found critical for the optimization of such antigen carriers [210]. For the delivery of antigen by the oral route, it has very recently been proposed to coat chitosan nanoparticles with alginate in order to prevent a burst released of the antigen in the intestinal medium and to further improve stability of the chitosan nanoparticles in this very aggressive medium [235].

Chitosan nanoparticles and chitosan-coated nanoparticles showed interesting bioadhesiveness on the cornea and good ocular tolerance. Their potential for the delivery of drugs at the ocular level was investigated. Both systems showed suitable delivery properties to improve topical administration of drugs at the level of the ocular mucosa [231]. Chitosan-coated nanoparticles, which are very versatile regarding their drug-loading capacity and release properties, increased the drug levels in cornea and aqueous humour to a significantly greater extent compared to the commercial drug preparation or to the drug-loaded uncoated nanoparticles. These nanoparticles were clearly able to enhance transportation of the drug across the cornea to reach the inner part of the eye. In contrast, chitosan nanoparticles accumulated into the corneal and conjunctival epithelia where increased concentration of drugs can be maintained for a prolonged duration. Initial experiments have indicated the adequate tolerance and low toxicity of these ocular drug carriers [73].

Several polysaccharides can form complex with nucleic acids. This property was exploited to formulate DNA loaded nanoparticles to deliver genes and antisens oligonucleotides in vivo. Most of the polysaccharide-based carriers were obtained from chitosan and alginate [7, 236]. In vitro, expression of gene transfected into cells using chitosan nanoparticles reached similar level than the expression level obtained with reference transfection agents including Lipofectin ${ }^{\circ}$ and Surperfect ${ }^{\circ}$ [237]. The nanoparticles presented high encapsulation efficiency and good protection of DNA from DNase digestion [238]. To further improve transfection properties of chitosan nanoparticles and enhance the specificity of the carrier toward the target cells, Manssouri et al suggested to attach folic acid residues on the nanoparticle surface [239]. Nanoparticles made of polyesters or silica coated with chitosan or modified chitosan may also serve as carriers for DNA plasmids or for antisens oligonucleotides [7, 61, 240-243]. In these nanoparticles, the nucleic acid is adsorbed on the carrier surface thanks to the formation of polyion complex with the polycationic polysaccharide standing at the nanoparticle surface. Another system made of alginate nanoparticles was reported to associate antisens oligonucleotides [244]. The stability of the associated oligonucleotides in presence of serum was considerably improved indicating that the carrier system may be suitable for the in vivo delivery of antisens oligonucleotides. The main objective of gene therapy is to obtain successful in vivo transfer of the genetic material to the targeted tissue. However, the growing potential of gene therapy will not achieve this goal until the issue of gene delivery has been resolved [245]. Naked DNA cannot be delivered efficiently. Consequently, good gene delivery formulations are needed requiring good encapsulation efficiency of DNA, protection from degradation and specific targeting to desired cells. The optimal system is still not found. The polysaccharide nanoparticles presenting so far good complexing and transfection efficiency are interesting potential systems. It may be expected that research on these systems will continue to grow and expand in the close future.

Polyanionic polysaccharides including heparin were shown to interact strongly with hemoglobin preserving its functionality as oxygen carrier [246]. This was exploited to load functional haemoglobin on heparin coated nanoparticles to be used as possible oxygen carrier for in vivo applications [247]. The nanoparticles having a diameter of $80 \mathrm{~nm}$ showed the highest haemoglobin-loaded capacity compared to other carrier systems. Indeed, they can associate up to $40 \mathrm{mg}$ haemoglobin per gram of nanoparticles while other nanoparticles showed one third of this loading capacity [247, 248]. The functionality of hemoglobin standing in the heparin corona at the nanoparticle surface was preserved as well as the anticoagulant activity of heparin. This system in which a drug may additionally be incorporated in the polymer core can constitute a new generation of multifunctional drug delivery system. 
Author version from Vauthier et al., In "Handbook of Pharmaceutical Biotechnology", 2007. https://doi.org/10.1002/9780470117118.ch1d

\section{CONCLUSION}

In the recent years, there has been a resurgence of interest in the biological role of carbohydrates. Active research which started a couple of years ago already highlighted the many biological roles and the diverse functions of carbohydrates in physiological and diseased processes. Several are useful for application as powerful drugs providing that they are specifically deliver to the diseased cells. Their combination with nanoparticle drug carriers may be required improving their efficacy and specificity at the target site. From another point of view, several polysaccharides appeared to be interesting constituents of drug carrier having remarkable mucoadhesive properties and promoting drug delivery by mucosal routes. The wide applications of carbohydrates in the design of drug delivery systems are isslutrated in figure 1.

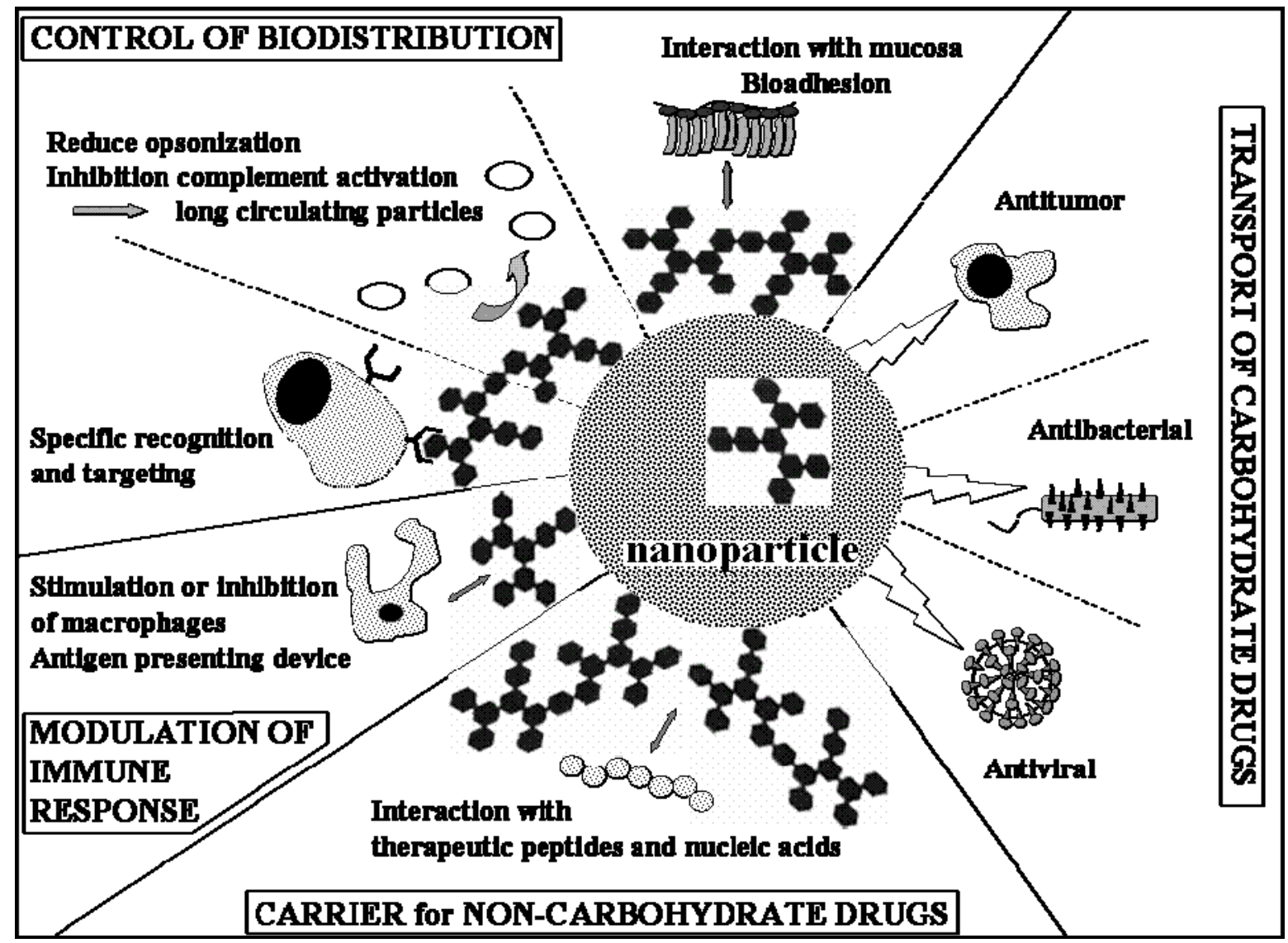

Figure 1: Diverse carbohydrate properties and their application in design of nanoparticle drug delivery system.

Carbohydrates based nanoparticles appeared to be well tolerated so far. However, full toxicological studies have not been performed yet and safety of the formulated delivery systems will be an important point to clarify in the near future for further development for in vivo use. Finally, because carbohydrates are implicated in many cell recognition mechanisms and cell signalling phenomena based on high specific interactions with corresponding cell receptors, they may provide very useful tools to increase targeting specificity of drug delivery systems towards defined cells in vivo. A considerable work remains to be done before all potential of carbohydrates will be depicted and ready to be integrated in the design of better-defined drug delivery systems with more precise functions. This will require the understanding of the role of biological functions of more carbohydrates found in Mother Nature and production or synthesis of sufficient amounts of the defined carbohydrate to clarify their functionalities. From the first results of the experiences done so far on quite simple systems, it may be expected carbohydrates they will allow to step over a new 
Author version from Vauthier et al., In "Handbook of Pharmaceutical Biotechnology", 2007. https://doi.org/10.1002/9780470117118.ch1d

milestone in the development of drug delivery systems integrating most recent developments in glycobiology.

\section{REFERENCES}

[1] T. Yoshida (2001). Synthesis of polysaccharides having specific biological activities. Progress in Polymer Science, 26, 379-441

[2] G. Venkataraman, Z. Shriver, R. Raman, R. Sasisekharan (1999). Sequencing complex polysaccharides. Science, 286, 537-542

[3] F. V. Toukach, A. S. Shashkov (2001). Computer-assisted structural analysis of regular glycopolymers on the basis of 13C NMR data. Carbohydrate Research, 335, 101-114

[4] Y. C. Lee (1996). Carbohydrate analyses with high-performance anion-exchange chromatography. Journal of Chromatography A, 720, 137-149

[5] H.-J. Gabius (2004). The sugar code in drug delivery. Advanced Drug Delivery Reviews, 56, 421-424

[6] C. Vauthier, P. Couvreur, Development of Polysaccharide Nanoparticles as Novel Drug Carrier Systems in Handbook of Pharmaceutical Controlled Release Technology, D. L. Wise, Marcel Dekker New York, 2000, 413-429

[7] K. A. Janes, P. Calvo, M. J. Alonso (2001). Polysaccharide colloidal particles as delivery systems for macromolecules. Advanced Drug Delivery Reviews, 47, 83-97

[8] C. Prego, M. Garcia, M. J. Alonso (2005). Transmucosal macromolecular drug delivery. J. Controlled Rel., 101, 151-162

[9] C. Vauthier, E. Fattal, D. Labarre, From polymer chemistry and physicochemistry to nanoparticulate drug carrier design and applications in Tissue Engineering and novel delivery system, M. J. Yaszemski, D. J. Trantolo, K. U. Lewandrowski, V. Hasirci, D. E. Altobelli and D. L. Wise, Marcel Dekker New York, 2004, 562-598

[10] A. Nori, J. Kopecek (2005). Intracellular targeting of polymer-bound drugs for cancer chemotherapy. Advanced Drug Delivery Reviews, 57, 609-636

[11] R. Duncan (2003). The dawning era of polymer therapeutics. Nature Reviews. Drug Discovery, 2, 347-360

[12] L. Nobs, F. Buchegger, R. Gurny, E. Allemann (2004). Current methods for attaching targeting ligands to liposomes and nanoparticles. Journal Of Pharmaceutical Sciences, 93, 1980-1992

[13] V. P. Torchilin (2005). Recent advances with liposomes as pharmaceutical carriers. Nat Rev Drug Discov, 4, 145-160

[14] S. M. Moghimi, J. Szebeni (2003). Stealth liposomes and long circulating nanoparticles: critical issues in pharmacokinetics, opsonization and protein-binding properties. Progress in Lipid Research, 42, 463-478

[15] S. M. Moghimi, A. C. Hunter, J. C. Murray (2001). Long-circulating and target-specific nanoparticles: theory to practice. Pharmacological Reviews, 53, 283-318

[16] G. Gregoriadis, B. McCormack, Z. Wang, R. Lifely (1993). Polysialic acids: potential in drug delivery. FEBS Lett, 315, 271-276

[17] J.-C. Olivier, C. Vauthier, M. Taverna, F. Puisieux, D. Ferrier, P. Couvreur (1996). Stability of orosomucoid-coated polyisobutylcyanoacrylate nanoparticles in the presence of serum. Journal of Controlled Release, 40, 157-168

[18] C. Passirani, L. Ferrarini, G. Barratt, J. P. Devissaguet, D. Labarre (1999). Preparation and characterization of nanoparticles bearing heparin or dextran covalently-linked to poly(methyl methacrylate). J Biomater Sci Polym Ed, 10, 47-62 
[19] C. Chauvierre, D. Labarre, P. Couvreur, C. Vauthier (2003). Novel polysaccharide-decorated poly(isobutyl cyanoacrylate) nanoparticles. Pharm Res, 20, 1786-1793

[20] I. Bertholon, C. Vauthier, D. Labarre Core-shell poly(isobutylcyanoacrylate)- polysaccharide nanoparticles: influences of surface morphology, length and type of polysaccharide on complement activation in vitro. submitted,

[21] I. Bertholon, G. Ponchel, D. Labarre, P. Couvreur, C. Vauthier Bioadhesive properties of poly(alkylcyanoacrylate) nanoparticles coated with polysaccharide. Submitted,

[22] V. Sihorkar, S. P. Vyas (2001). Potential of polysaccharide anchored liposomes in drug delivery, targeting and immunization. J Pharm Pharmceut Sci, 4, 138-158

[23] S. Drotleff, U. Lungwitz, M. Breunig, A. Dennis, T. Blunk, J. Tessmar, A. Gopferich (2004). Biomimetic polymers in pharmaceutical and biomedical sciences. European Journal of Pharmaceutics and Biopharmaceutics, 58, 385-407

[24] I. Bravo-Osuna, T. Schmith, A. Bernkop-Schnurch, C. Vauthier, G. Ponchel Elaboration and characterization of thiolated chitosan-coated acrylic nanoparticles. Submitted,

[25] E. H. Eylar (1966). On the biological role of glycoproteins. Journal of Theoretical Biology, 10, 89113

[26] T. Kimmerlin, D. Seebach (2005). '100 years of peptide synthesis': ligation methods for peptide and protein synthesis with applications to beta-peptide assemblies. The Journal Of Peptide Research: Official Journal Of The American Peptide Society, 65, 229-260

[27] P. Zamecnik (2005). From protein synthesis to genetic insertion. Annual Review Of Biochemistry, $74,1-28$

[28] N. Sharon, H. Lis (2004). History of lectins: from hemagglutinins to biological recognition molecules. Glycobiology, 14, 53R-62R

[29] S. M. Khersonsky, C. M. Ho, M.-A. F. Garcia, Y.-T. Chang (2003). Recent advances in glycomics and glycogenetics. Current Topics In Medicinal Chemistry, 3, 617-643

[30] M. Petitou, B. Casu, U. Lindahl (2003). 1976-1983, a critical period in the history of heparin: the discoveryof the antithrombin binding site. Biochimie, 85, 83-89

[31] C. Passirani, G. Barratt, J.-P. Devissaguet, D. Labarre (1998). Interactions of nanoparticles bearing heparin or dextran covalently bound to poly(methyl methacrylate) with the complement system. Life Sciences, 62, 775-785

[32] D. Labarre, C. Vauthier, C. Chauvierre, B. Petri, R. Muller, M. M. Chehimi (2005). Interactions of blood proteins with poly(isobutylcyanoacrylate) nanoparticles decorated with a polysaccharidic brush. Biomaterials, 26, 5075-5084

[33] A. Di Marco, G. Cassinelli, F. Arcamone (1981). The discovery of daunorubicin. Cancer Treatment Reports, 65, 3-8

[34] H.M. Osborn, P.G. Evans, N. Gemmel, S.D. Osborne (2004). Carbohydrate-based therapeutics. J Pharm Pharmacol. 56, 691-702.

[35] J.J. Barchi (2000). Emerging roles of carbohydrates and glycomimetics in anticancer drug design. Curr Pharm Des. 6, 485-501.

[36] M. A. Kabel, H. A. Schols,A. G. J. Voragen (2001). Mass determination of oligosaccharides by matrix-assisted laser desorption/ionization time-of-flight mass spectrometry following HPLC, assisted by on-line desalting and automated sample handling. Carbohydrate Polymers, 44, 161-165

[37] A. Broberg, K. K. Thomsen, J. O. Duus (2000). Application of nano-probe NMR for structure determination of low nanomole amounts of arabinoxylan oligosaccharides fractionated by analytical HPAEC-PAD. Carbohydrate Research, 328, 375-382

[38] W. Morelle, J.-C. Michalski (2005). Glycomics and mass spectrometry. Current Pharmaceutical Design, 11, 2615-2645 
Author version from Vauthier et al., In "Handbook of Pharmaceutical Biotechnology", 2007. https://doi.org/10.1002/9780470117118.ch1d

[39] M. Iwafune, I. Kakizaki, H. Nakazawa, I. Nukatsuka, M. Endo, K. Takagaki (2004). A glycomic approach to proteoglycan with a two-dimensional polysaccharide chain map. Analytical Biochemistry, 325, 35-40

[40] D. M. Ratner, E. W. Adams, M. D. Disney, P. H. Seeberger (2004). Tools for glycomics: mapping interactions of carbohydrates in biological systems. Chembiochem: a European Journal Of Chemical Biology, 5, 1375-1383

[41] D. N. Howbrook, A. M. van der Valk, M. C. O'Shaughnessy, D. K. Sarker, S. C. Baker, A. W. Lloyd (2003). Developments in microarray technologies. Drug Discovery Today, 8, 642-651

[42] R. R. Vives, S. Goodger, D. A. Pye (2001). Combined strong anion-exchange HPLC and PAGE approach for the purification of heparan sulphate oligosaccharides. The Biochemical Journal, $354,141-147$

[43] O. J. Plante (2005). Combinatorial chemistry in glycobiology. Combinatorial Chemistry \& High Throughput Screening, 8, 153-159

[44] A. Holemann, P. H. Seeberger (2004). Carbohydrate diversity: synthesis of glycoconjugates and complex carbohydrates. Current Opinion in Biotechnology, 15, 615-622

[45] M. Köhn, R. Breinbauer (2004). The Staudinger ligation-a gift to chemical biology. Angew Chem Int Ed Engl. 43, 3106-3116.

[46] M. de Kort, R. C. Buijsman, C. A. A. van Boeckel (2005). Synthetic heparin derivatives as new anticoagulant drugs. Drug Discovery Today, 10, 769-779

[47] S. L. Croft, G. H. Coombs (2003). Leishmaniasis--current chemotherapy and recent advances in the search for novel drugs. Trends Parasitol, 19, 502-508

[48] J. P. Adler-Moore, R. T. Proffitt (1993). Development, characterization, efficacy and mode of action of ambisome ${ }^{(R)}$. J. Loposome Res., 3, 429-450

[49] P. Couvreur, G. Barratt, E. Fattal, P. Legrand, C. Vauthier (2002). Nanocapsule technology: a review. Crit Rev Ther Drug Carrier Syst, 19, 99-134

[50] C. Vauthier, C. Dubernet, C. Chauvierre, I. Brigger, P. Couvreur (2003). Drug delivery to resistant tumors: the potential of poly(alkyl cyanoacrylate) nanoparticles. J Control Release, 93, 151160

[51] M. J. Alonso (2004). Nanomedicines for overcoming biological barriers. Biomedecine \& Pharmacotherapy, 58, 168-172

[52] M. Fouarge, M. Dewulf, P. Couvreur, M. Roland, H. Vranckx (1989). Development of dehydroemetine nanoparticles for the treatment of visceral leishmaniasis. Journal Of Microencapsulation, 6, 29-34

[53] R. Gaspar, V. Preat, F. R. Opperdoes, M. Roland (1992). Macrophage activation by polymeric nanoparticles of polyalkylcyanoacrylates: activity against intracellular Leishmania donovani associated with hydrogen peroxide production. Pharmaceutical Research, 9, 782-787

[54] J. Kattan, J. P. Droz, P. Couvreur, J. P. Marino, A. Boutan-Laroze, P. Rougier, P. Brault, H. Vranckx, J. M. Grognet, A. Morge et (1992). Phase I clinical trial and pharmacokinetic evaluation of doxorubicin carried by polyisohexylcyanoacrylate nanoparticles. Investigational New Drugs, 10, 191-199

[55] L. Barraud, P. Merle, E. Soma, L. Lefrancois, S. Guerret, M. Chevallier, C. Dubernet, P. Couvreur, C. Trepo, L. Vitvitski (2005). Increase of doxorubicin sensitivity by doxorubicin-loading into nanoparticles for hepatocellular carcinoma cells in vitro and in vivo. Journal of Hepatology, 42, 736-743

[56] B. Sangro (2005). Refined tools for the treatment of hepatocellular carcinoma. J Hepatol. 42, 629-631.

[57] R. Tyagi, S. Lala, A. K. Verma, A. K. Nandy, S. B. Mahato, A. Maitra, M. K. Basu (2005). Targeted delivery of arjunglucoside I using surface hydrophilic and hydrophobic nanocarriers to combat experimental leishmaniasis. J. Drug. Target., 13, 161-171 
Author version from Vauthier et al., In "Handbook of Pharmaceutical Biotechnology", 2007. https://doi.org/10.1002/9780470117118.ch1d

[58] S. Stolnik, S. E. Dunn, M. C. Garnett, M. C. Davies, A. G. Coombes, D. C. Taylor, M. P. Irving, S. C. Purkiss, T. F. Tadros, A. Davis (1994). Surface modification of poly(lactide-co-glycolide) nanospheres by biodegradable poly(lactide)-poly(ethylene glycol) copolymers. Pharmaceutical Research, 11, 1800-1808

[59] R. Gref, Y. Minamitake, M. T. Peracchia, V. Trubetskoy, V. Torchilin, R. Langer (1994). Biodegradable long-circulating polymeric nanospheres. Science, 263, 1600-1603

[60] C. Vauthier, P. Couvreur, Biodegradation of poly(alkylcyanoacrylates) in Handbook of Biopolymers, J. P. Matsumara and A. Steinbuchel, Wiley-VHC Weinheim Germany, 2002, 457490

[61] M. N. V. Ravi Kumar, U. Bakowsky, C. M. Lehr (2004). Preparation and characterization of cationic PLGA nanospheres as DNA carriers. Biomaterials, 25, 1771-1777

[62] I. Bertholon-Rajot, D. Labarre, C. Vauthier (2005). Influence of the initiator system, ceriumpolysaccharide, on the surface properties of poly(isobutylcyanoacrylate) nanoparticles. Polymer, 46, 1407-1415

[63] N. G. M. Schipper, S. Olsson, J. A. Hoogstraate, A. G. deBoer, K. M. Varum, P. Artursson (1997). Chitosans as Absorption Enhancers for Poorly Absorbable Drugs 2: Mechanism of Absorption Enhancement. Pharmaceutical Research, 14, 923-929

[64] J. M. Smith, M. Dornish, E. J. Wood (2005). Involvement of protein kinase C in chitosan glutamate-mediated tight junction disruption. Biomaterials, 26, 3269-3276

[65] C.-M. Lehr, J. A. Bouwstra, E. H. Schacht, H. E. Junginger (1992). In vitro evaluation of mucoadhesive properties of chitosan and some other natural polymers. International Journal of Pharmaceutics, 78, 43-48

[66] N. G. Schipper, K. M. Varum, P. Artursson (1996). Chitosans as absorption enhancers for poorly absorbable drugs. 1: Influence of molecular weight and degree of acetylation on drug transport across human intestinal epithelial (Caco-2) cells. Pharm Res, 13, 1686-1692

[67] S. Y. Chae, M.-K. Jang, J.-W. Nah (2005). Influence of molecular weight on oral absorption of water soluble chitosans. Journal of Controlled Release, 102, 383-394

[68] M. Thanou, J. C. Verhoef, H. E. Junginger (2001). Oral drug absorption enhancement by chitosan and its derivatives. Adv Drug Deliv Rev, 52, 117-126

[69] M. R. Avadi, A. Jalali, A. M. M. Sadeghi, K. Shamimi, K. H. Bayati, E. Nahid, A. R. Dehpour, M. Rafiee-Tehrani (2005). Diethyl methyl chitosan as an intestinal paracellular enhancer: ex vivo and in vivo studies. International Journal of Pharmaceutics, 293, 83-89

[70] G. Sandri, S. Rossi, F. Ferrari, M. C. Bonferoni, C. Muzzarelli, C. Caramella (2004). Assessment of chitosan derivatives as buccal and vaginal penetration enhancers. Eur J Pharm Sci, 21, 351-359

[71] K. Kafedjiiski, F. Föger, M. Werle, A. Bernkop-Schnürch (2005). Synthesis and in Vitro Evaluation of a Novel Chitosan-Glutathione Conjugate. Pharmaceutical Research, 22, 1480-1488

[72] A. Bernkop-Schnurch, Y. Pinter, D. Guggi, H. Kahlbacher, G. Schoffmann, M. Schuh, I. Schmerold, M. D. Del Curto, M. D'Antonio, P. Esposito, C. Huck (2005). The use of thiolated polymers as carrier matrix in oral peptide delivery--Proof of concept. Journal of Controlled Release, 106, 26-33

[73] A. M. De Campos, A. Sanchez, R. Gref, P. Calvo, M. J. Alonso (2003). The effect of a PEG versus a chitosan coating on the interaction of drug colloidal carriers with the ocular mucosa. European Journal of Pharmaceutical Sciences, 20, 73-81

[74] H. Yamamoto, H. Takeuchi, T. Hino, Y. Kawashima (2000). Mucoadhesive liposomes: physicochemical properties and release behavior of water-soluble drugs from chitosan-coated liposomes. S.T.P. Pharma Sci, 10, 63-68

[75] P. Calvo, J. L. Vila-Jato, M. J. Alonso (1997). Evaluation of cationic polymer-coated nanocapsules as ocular drug carriers. International Journal of Pharmaceutics, 153, 41-50 
Author version from Vauthier et al., In "Handbook of Pharmaceutical Biotechnology", 2007. https://doi.org/10.1002/9780470117118.ch1d

[76] H. Yamamoto, Y. Kuno, S. Sugimoto, H. Takeuchi, Y. Kawashima (2005). Surface-modified PLGA nanosphere with chitosan improved pulmonary delivery of calcitonin by mucoadhesion and opening of the intercellular tight junctions. Journal of Controlled Release, 102, 373-381

[77] I. Messai, T. Delair (2005). Adsorption of Chitosan onto Poly(D,L-lactic acid) Particles: A PhysicoChemical Investigation. Macromolecular Chemistry and Physics, 206, 1665-1674

[78] S. C. Yang, H. X. Ge, Y. Hu, X. Q. Jiang, C. Z. Yang (2000). Formation of positively charged poly(butyl cyanoacrylate) nanoparticles stabilized with chitosan. Colloid Polym Sci, 278, 285292

[79] G. Ponchel, J. Irache (1998). Specific and non-specific bioadhesive particulate systems for oral delivery to the gastrointestinal tract. Adv Drug Deliv Rev, 34, 191-219

[80] C. Valenta (2005). The use of mucoadhesive polymers in vaginal delivery. Advanced Drug Delivery Reviews, 57, 1692-1712

[81] Y. Song, Y. Wang, R. Thakur, V. M. Meidan, B. Michniak (2004). Mucosal drug delivery: membranes, methodologies, and applications. Crit Rev Ther Drug Carrier Syst, 21, 195-256

[82] S. Barbault-Foucher, R. Gref, P. Russo, J. Guechot, A. Bochot (2002). Design of poly-ecaprolactone nanosphere coated with bioadhesive hyaluronic acid for ocular delivery. Journal of Controlled Release, 83, 365-375

[83] J.-C. Leroux, F. De Jaeghere, B. Anner, E. Doelker, R. Gurny (1995). An investigation on the role of plasma and serum opsonins on the evternalization of biodegradable poly( $D, L$-lactic acid) nanoparticles by human monocytes. Life Sciences, 57, 695-703

[84] V. Lenaerts, J. F. Nagelkerke, T. J. Van Berkel, P. Couvreur, L. Grislain, M. Roland, P. Speiser (1984). In vivo uptake of polyisobutyl cyanoacrylate nanoparticles by rat liver Kupffer, endothelial, and parenchymal cells. Journal Of Pharmaceutical Sciences, 73, 980-982

[85] C. Lemarchand, R. Gref, P. Couvreur (2004). Polysaccharide-decorated nanoparticles. European Journal of Pharmaceutics and Biopharmaceutics, 58, 327-341

[86] V. P. Torchilin (2000). Drug targeting. European Journal Of Pharmaceutical Sciences: Official Journal Of The European Federation For Pharmaceutical Sciences, 11, S81-S91

[87] D. E. Owens III, N. A. Peppas Opsonization, biodistribution, and pharmacokinetics of polymeric nanoparticles. International Journal of Pharmaceutics, In Press, Corrected Proof,

[88] V. P. Torchilin, V. S. Trubetskoy (1995). Which polymers can make nanoparticulate drug carriers long-circulating? Advanced Drug Delivery Reviews, 16, 141-155

[89] C. Passirani, G. Barratt, J. P. Devissaguet, D. Labarre (1998). Long-circulating nanoparticles bearing heparin or dextran covalently bound to poly(methyl methacrylate). Pharm Res, 15, 1046-1050

[90] C. Lemarchand, R. Gref, C. Passirani, E. Garcion, B. Petri, R. Muller, D. Costantini, P. Couvreur (2006). Influence of polysaccharide coating on the interactions of nanoparticles with biological systems. Biomaterials, 27, 108-118

[91] N. Jaulin, M. Appel, C. Passirani, G. Barratt, D. Labarre (2000). Reduction of the uptake by a macrophagic cell line of nanoparticles bearing heparin or dextran covalently bound to poly(methyl methacrylate). Journal Of Drug Targeting, 8, 165-172

[92] C. Rouzes, R. Gref, M. Leonard, A. De Sousa Delgado, E. Dellacherie (2000). Surface modification of poly(lactic acid) nanospheres using hydrophobically modified dextrans as stabilizers in an o/w emulsion/evaporation technique. Journal Of Biomedical Materials Research, 50, 557-565

[93] M. P. Carreno, F. Maillet, D. Labarre, M. Jozefowicz, M. D. Kazatchkine (1988). Specific antibodies enhance Sephadex-induced activation to the alternative pathway in human serum. Biomaterials, 9, 514-518

[94] J.-C. Olivier, Développement d'un vecteur biomimétique, PhD, Université Paris 11, Faculté de Pharmacie, Chatenay-Malabry, 1995, 133 
Author version from Vauthier et al., In "Handbook of Pharmaceutical Biotechnology", 2007. https://doi.org/10.1002/9780470117118.ch1d

[95] A. Maruyama, T. Ishihara, J. S. Kim, S. W. Kim, T. Akaike (1997). Nanoparticle DNA carrier with poly(L-lysine) grafted polysaccharide copolymer and poly(D,L-lactic acid). Bioconjug Chem, 8, 735-742

[96] J. Benesch, P. Tengvall (2002). Blood protein adsorption onto chitosan. Biomaterials, 23, 25612568

[97] S. Minami, H. Suzuki, Y. Okamoto, T. Fujinaga, Y. Shigemasa (1998). Chitin and chitosan activate complement via the alternative pathway. Carbohydrate Polymers, 36, 151-155

[98] Y. Suzuki, Y. Okamoto, M. Morimoto, H. Sashiwa, H. Saimoto, S. I. Tanioka, Y. Shigemasa, S. Minami (2000). Influence of physico-chemical properties of chitin and chitosan on complement activation. Carbohydrate Polymers, 42, 307-310

[99] S. Mitra, U. Gaur, P. C. Ghosh, A. N. Maitra (2001). Tumour targeted delivery of encapsulated dextran-doxorubicin conjugate using chitosan nanoparticles as carrier. J Control Release, 74, 317-323

[100] T. Banerjee, S. Mitra, A. Kumar Singh, R. Kumar Sharma, A. Maitra (2002). Preparation, characterization and biodistribution of ultrafine chitosan nanoparticles. International Journal of Pharmaceutics, 243, 93-105

[101] T. Banerjee, A. K. Singh, R. K. Sharma, A. N. Maitra (2005). Labeling efficiency and biodistribution of Technetium-99m labeled nanoparticles: interference by colloidal tin oxide particles. International Journal of Pharmaceutics, 289, 189-195

[102] Y. J. Son, J.-S. Jang, Y. W. Cho, H. Chung, R.-W. Park, I. C. Kwon, I.-S. Kim, J. Y. Park, S. B. Seo, C. R. Park, S. Y. Jeong (2003). Biodistribution and anti-tumor efficacy of doxorubicin loaded glycol-chitosan nanoaggregates by EPR effect. Journal of Controlled Release, 91, 135-145

[103] Y. Kato, H. Onishi, Y. Machida (2000). Evaluation of N-succinyl-chitosan as a systemic longcirculating polymer. Biomaterials, 21, 1579-1585

[104] J. Hyung Park, S. Kwon, M. Lee, H. Chung, J.-H. Kim, Y.-S. Kim, R.-W. Park, I.-S. Kim, S. Bong Seo, I. C. Kwon, S. Young Jeong (2006). Self-assembled nanoparticles based on glycol chitosan bearing hydrophobic moieties as carriers for doxorubicin: In vivo biodistribution and antitumor activity. Biomaterials, 27, 119-126

[105] R. Schauer (1985). Sialic acids and their role as biological masks. Trends Biochem. Sci., 10, 357360

[106] J. R. Durocher, R. C. Payne, M. E. Conrad (1975). Role of sialic acid in erythrocyte survival. Blood, 45, 11-20

[107] R. Schauer, Sialic acids regulate cellular and molecular recognition in Carbohydrates, H. Ogura, A. Hasegawa and T. Suami, Kodansha Ltd Tokyo, 1992, 340-354

[108] J. Jancik, R. Schauer (1974). Sialic acid--a determinant of the life-time of rabbit erythrocytes. Hoppe Seylers Z Physiol Chem, 355, 395-400

[109] J. Jancik, R. Schauer, K. H. Anders, M. von Düring (1978). Sequestration of neuraminidasetreated erythrocytes. Cell Tiss. Res., 186, 209-226

[110] D. D. Ourth, L. M. Bachinski (1987). Bacterial sialic acid modulates activation of the alternative complement pathway of channel catfish ( ). Developmental \& Comparative Immunology, 11, 551-564

[111] S. Sakarya, S. Oncu (2003). Bacterial adhesins and the role of sialic acid in bacterial adhesion. Medical Science Monitor: International Medical Journal Of Experimental And Clinical Research, 9, RA76-RA82

[112] E. R. Vimr, K. A. Kalivoda, E. L. Deszo, S. M. Steenbergen (2004). Diversity of Microbial Sialic Acid Metabolism. Microbiol. Mol. Biol. Rev., 68, 132-153

[113] J. C. Olivier, M. Taverna, C. Vauthier, P. Couvreur, D. Baylocq-Ferrier (1994). Capillary electrophoresis monitoring of the competitive adsorption of albumin onto the orosomucoidcoated polyisobutylcyanoacrylate nanoparticles. Electrophoresis, 15, 234-239 
Author version from Vauthier et al., In "Handbook of Pharmaceutical Biotechnology", 2007. https://doi.org/10.1002/9780470117118.ch1d

[114] P. Huve, Comprendre et éviter la capture des nanoparticules de poly(acidelactique) par le système des phagocytes mononucléaires, PhD, Université Paris Sud, Faculty of Pharmacy, Chatenay Malabry, 1994, 193

[115] H. Yamauchi, T. Yano, T. Kato, I. Tanaka, S. Nakabayashi, K. Higashi, S. Miyoshi, H. Yamada (1995). Effects of sialic acid derivative on long circulation time and tumor concentration of liposomes. International Journal of Pharmaceutics, 113, 141-148

[116] M. D. Kazatchkine, D. T. Fearon, J. E. Silbert, K. F. Austen (1979). Surface-associated heparin inhibits zymosan-induced activation of the human alternative complement pathway by augmenting the regulatory action of the control proteins on particle-bound C3b. J Exp Med, $150,1202-1215$

[117] J. F. Keuren, S. J. Wielders, G. M. Willems, M. Morra, L. Cahalan, P. Cahalan, T. Lindhout (2003). Thrombogenicity of polysaccharide-coated surfaces. Biomaterials, 24, 1917-1924

[118] N. Weber, H. P. Wendel, G. Ziemer (2002). Hemocompatibility of heparin-coated surfaces and the role of selective plasma protein adsorption. Biomaterials, 23, 429-439

[119] S. C. Jeong, B. K. Yang, K. S. Ra, M. A. Wilson, Y. Cho, Y. A. Gu, C. H. Song (2004). Characteristics of anti-complementary biopolymer extracted from Coriolus versicolor. Carbohydrate Polymers, 55, 255-263

[120] N. Yamazaki, S. Kojima, N. V. Bovin, S. Andre, S. Gabius, H.-J. Gabius (2000). Endogenous lectins as targets for drug delivery. Advanced Drug Delivery Reviews, 43, 225-244

[121] C. Ehrhardt, C. Kneuer, U. Bakowsky (2004). Selectins-an emerging target for drug delivery. Advanced Drug Delivery Reviews, 56, 527-549

[122] N. Yamazaki, S. Kojima, H. Yokoyama (2005). Biomedical nanotechnology for active drug delivery systems by applying sugar-chain molecular functions. Current Applied Physics, 5, 112117

[123] C. Bies, C.-M. Lehr, J. F. Woodley (2004). Lectin-mediated drug targeting: history and applications. Advanced Drug Delivery Reviews, 56, 425-435

[124] V. Faivre, M. d. L. Costa, P. Boullanger, A. Baszkin, V. Rosilio (2003). Specific interaction of lectins with liposomes and monolayers bearing neoglycolipids. Chemistry and Physics of Lipids, 125, 147-159

[125] E. Forssen, M. Willis (1998). Ligand-targeted liposomes. Adv Drug Deliv Rev, 29, 249-271

[126] T. Minko (2004). Drug targeting to the colon with lectins and neoglycoconjugates. Advanced Drug Delivery Reviews, 56, 491-509

[127] C.-M. Lehr, F. Gabor (2004). Lectins and glycoconjugates in drug delivery and targeting. Advanced Drug Delivery Reviews, 56, 419-420

[128] M. J. Montisci, G. Giovannuci, D. Duchene, G. Ponchel (2001). Covalent coupling of asparagus pea and tomato lectins to poly(lactide) microspheres. Int J Pharm, 215, 153-61

[129] J. A. Reddy, V. M. Allagadda, C. P. Leamon (2005). Targeting therapeutic and imaging agents to folate receptor positive tumors. Curr Pharm Biotechnol, 6, 131-50

[130] S. Gao, J. Chen, L. Dong, Z. Ding, Y.-h. Yang, J. Zhang (2005). Targeting delivery of oligonucleotide and plasmid DNA to hepatocyte via galactosylated chitosan vector. European Journal of Pharmaceutics and Biopharmaceutics, 60, 327-334

[131] A.L. Hubbard, G. Wilson, G. Ashwell, H. Stukenbrok (1979). H. An electron microscope autoradiographic study of the carbohydrate recognition systems in rat liver. I. Distribution of 125I-ligands among the liver cell types. J Cell Biol. 83, 47-64

[132] U. Kishore, P. Eggleton, K.B. Reid (1997). Modular organization of carbohydrate recognition domains in animal lectins. Matrix Biol. 15, 583-592

[133] T. Tanaka, Y. Fujishima, S. Hanano, Y. Kaneo (2004). Intracellular disposition of polysaccharides in rat liver parenchymal and nonparenchymal cells. Int J Pharm. 286, 9-17.

[134] C. Blondin, L. Bataille, D. Letourneur (2000). Polysaccharides for vascular cell targeting. Crit Rev Ther Drug Carrier Syst. 17, 327-375. 
Author version from Vauthier et al., In "Handbook of Pharmaceutical Biotechnology", 2007. https://doi.org/10.1002/9780470117118.ch1d

[135] K.P. Vercruysse, G.D. Prestwich (1998). Hyaluronate derivatives in drug delivery. Crit Rev Ther Drug Carrier Syst. 15, 513-555.

[136] M.S. Sy, Y.J. Guo, I. Stamenkovic (1991). Distinct effects of two CD44 isoforms on tumor growth in vivo. J Exp Med. 174, 859-866.

[137] Y. Luo, N. J. Bernshaw, Z.-R. Lu, J. Kopecek,G. D. Prestwich (2002). Targeted Delivery of Doxorubicin by HPMA Copolymer-Hyaluronan Bioconjugates. Pharmaceutical Research, 19, 396-402

[138] U. Gunthert, M. Hofmann, W. Rudy, S. Reber, M. Zoller, I. Haussmann, S. Matzku, A. Wenzel, H. Ponta, P. Herrlich (1991). A new variant of glycoprotein CD44 confers metastatic potential to rat carcinoma cells. Cell. 65, 13-24.

[139] J. Entwistle, C.L. Hall, E.A. Turley (1996). HA receptors: regulators of signalling to the cytoskeleton. J Cell Biochem. 61, 569-577.

[140] A. Danguy, I. Camby, R. Kiss (2002). Galectins and cancer. Biochim Biophys Acta. 1572, 285-293.

[141] P. J. Julyan, L. W. Seymour, D. R. Ferry, S. Daryani, C. M. Boivin, J. Doran, M. David, D. Anderson, C. Christodoulou, A. M. Young (1999). Preliminary clinical study of the distribution of HPMA copolymers bearing doxorubicin and galactosamine. Journal of Controlled Release, 57, 281290

[142] K. D. Jensen, P. Kopeckova, J. H. Bridge, J. Kopecek (2001). The cytoplasmic escape and nuclear accumulation of endocytosed and microinjected HPMA copolymers and a basic kinetic study in Hep G2 cells. AAPS PharmSci, 3, E32

[143] G.-Y. Kim, G.-S. Choi, S.-H. Lee, Y.-M. Park (2004). Acidic polysaccharide isolated from Phellinus linteus enhances through the up-regulation of nitric oxide and tumor necrosis factor-[alpha] from peritoneal macrophages. Journal of Ethnopharmacology, 95, 69-76

[144] X. Q. Zhang, X. L. Wang, P. C. Zhang, Z. L. Liu, R. X. Zhuo, H. Q. Mao, K. W. Leong (2005). Galactosylated ternary DNA/polyphosphoramidate nanoparticles mediate high gene transfection efficiency in hepatocytes. J Control Release, 102, 749-763

[145] C. Wu, J. Wilson, G. Wu (1989). Targeting genes: delivery and persistent expression of a foreign gene driven by mammalian regulatory elements in vivo. J. Biol. Chem., 264, 16985-16987

[146] J. Wilson, M. Grossman, C. Wu, N. Chowdhury, G. Wu, J. Chowdhury (1992). Hepatocytedirected gene transfer in vivo leads to transient improvement of hypercholesterolemia in low density lipoprotein receptor- deficient rabbits. J. Biol. Chem., 267, 963-967

[147] I. Fajac, G. Thévenot, L. Bédouet, C. Danel, M. Riquet, M. Merten, C. Figarella, J. Dall' AvaSantucci, M. Monsigny, P. Briand (2003). Uptake of plasmid/glycosylated polymer complexes and gene transfer efficiency in differentiated airway epithelial cells. The Journal of Gene Medicine, 5, 38-48

[148] D. Cade, E. Ramus, M. Rinaudo, R. Auzély-Velty, T. Delair, T. Hamaide (2004). Tailoring of bioresorbable polymers for elaboration of sugar-functionalized nanoparticles. Biomacromolecules, 5, 922-927

[149] C. Racles, T. Hamaide (2005). Synthesis and Characterization of Water Soluble Saccharide Functionalized Polysiloxanes and Their Use as Polymer Surfactants for the Stabilization of Polycaprolactone Nanoparticles. Macromolecular Chemistry and Physics, 206, 1757-1768

[150] Y.-I. Jeong, S.-J. Seo, I.-K. Park, H.-C. Lee, I.-C. Kang, T. Akaike, C.-S. Cho (2005). Cellular recognition of paclitaxel-loaded polymeric nanoparticles composed of poly([gamma]-benzyl Iglutamate) and poly(ethylene glycol) diblock copolymer endcapped with galactose moiety. International Journal of Pharmaceutics, 296, 151-161

[151] T. Uchida, T. Serizawa, H. Ise, T. Akaike, M. Akashi (2001). Graft copolymer having hydrophobic backbone and hydrophilic branches. 33. Interaction of hepatocytes and polystyrene nanospheres having lactose-immobilized hydrophilic polymers on their surfaces. Biomacromolecules, 2, 1343-1346 
Author version from Vauthier et al., In "Handbook of Pharmaceutical Biotechnology", 2007. https://doi.org/10.1002/9780470117118.ch1d

[152] V. R. Sinha, R. Kumria (2001). Polysaccharides in colon-specific drug delivery. Int J Pharm, 224, 19-38

[153] M. Jozefowicz, J. Jozefonvicz (1997). Randomness and biospecificity: random copolymers are capable of biospecific molecular recognition in living systems. Biomaterials, 18, 1633-1644

[154] J. B. Walker (2002). Enzymatic synthesis of aminoglycoside antibiotics: novel adenosylmethionine:2-deoxystreptamine $\mathrm{N}$-methyltransferase activities in hygromycin $\mathrm{B}$ - and spectinomycin-producing Streptomyces spp. and uses of the methylated products. Appl Environ Microbiol, 68, 2404-2410

[155] D. Macmillan, A. M. Daines (2003). Recent developments in the synthesis and discovery of oligosaccharides and glycoconjugates for the treatment of disease. Curr Med Chem, 10, 27332773

[156] C. H. Wong, M. C. Bryan, P. T. Nyffeler, H. Liu, E. Chapman (2003). Synthesis of carbohydratebased antibiotics. Pure Appl. Chem., 75, 179-186

[157] M. K. Basu,S. Lala (2004). Macrophage specific drug delivery in experimental leishmaniasis. Curr Mol Med, 4, 681-689

[158] P. R. Donald, F. A. Sirgel, A. Venter, E. Smit, D. P. Parkin, B. W. Van de Wal, D. A. Mitchison (2001). The early bactericidal activity of a low-clearance liposomal amikacin in pulmonary tuberculosis. J Antimicrob Chemother, 48, 877-880

[159] R. M. Fielding, R. O. Lewis, L. Moon-McDermott (1998). Altered tissue distribution and elimination of amikacin encapsulated in unilamellar, low-clearance liposomes (MiKasome). Pharm Res, 15, 1775-1781

[160] R. M. Fielding, L. Moon-McDermott, R. O. Lewis, M. J. Horner (1999). Pharmacokinetics and urinary excretion of amikacin in low-clearance unilamellar liposomes after a single or repeated intravenous administration in the rhesus monkey. Antimicrob Agents Chemother, 43, 503-509

[161] E. Fattal, M. Youssef, P. Couvreur, A. Andremont (1989). Treatment of experimental salmonellosis in mice with ampicillin-bound nanoparticles. Antimicrob Agents Chemother, 33, 1540-1543

[162] H. Pinto-Alphandary, A. Andremont, P. Couvreur (2000). Targeted delivery of antibiotics using liposomes and nanoparticles: research and applications. Int J Antimicrob Agents, 13, 155-168

[163] R. Schiffelers, G. Storm, I. Bakker-Woudenberg (2001). Liposome-encapsulated aminoglycosides in pre-clinical and clinical studies. J Antimicrob Chemother, 48, 333-344

[164] G. Barratt (2003). Colloidal drug carriers: achievements and perspectives. Cellular and Molecular Life Sciences (CMLS), 60, 21-37

[165] E. Fattal, O. Balland, H. Alphandary, S. Pecquet, F. Puisieux, P. Couvreur,A. Andremont, Colloidal carriers of antibiotics as an alternative approach for the treatment of intracellular infections in Antimicrobial agents and intracellular pathogens, D. Raoult, CRC Press Boca Raton, 1993, 6372

[166] S. Senel, S. J. McClure (2004). Potential applications of chitosan in veterinary medicine. Advanced Drug Delivery Reviews, 56, 1467-1480

[167] E. I. Rabea, M. E.-T. Badawy, C. V. Stevens, G. Smagghe, W. Steurbaut (2003). Chitosan as antimicrobial agent : applications and mode of action. Biomacromolecules, 4, 1457-1465

[168] Y. J. Jeon, P. J. Park, S. K. Kim (2001). Antimicrobial effect of chitooligosaccharides produced by bioreactor. Carbohydrate Polymers, 44, 71-76

[169] L. Y. Zheng, J. F. Zhu (2003). Study on antimicrobial activity of chitosan with different molecular weights. Carbohydrate Polymers, 54, 527-530

[170] H. Liu, Y. Du, X. Wang, L. Sun (2004). Chitosan kills bacteria through cell membrane damage. International Journal of Food Microbiology, 95, 147-155

[171] M. R. Avadi, A. M. M. Sadeghi, A. Tahzibi, K. Bayati, M. Pouladzadeh, M. J. Zohuriaan-Mehr, M. Rafiee-Tehrani (2004). Diethylmethyl chitosan as an antimicrobial agent: Synthesis, characterization and antibacterial effects. European Polymer Journal, 40, 1355-1361 
Author version from Vauthier et al., In "Handbook of Pharmaceutical Biotechnology", 2007. https://doi.org/10.1002/9780470117118.ch1d

[172] M. J. Carlucci, C. A. Pujol, M. Ciancia, M. D. Noseda, M. C. Matulewicz, E. B. Damonte, A. S. Cerezo (1997). Antiherpetic and anticoagulant properties of carrageenans from the red seaweed Gigartina skottsbergii and their cyclized derivatives:correlation between structure and biological activity. Int J Biol Macromol, 20, 97-105

[173] R. L. Yoshida, H. Nakashima, M. Premanathan, R. Aragaki, T. Mimura, Y. Kaneko, N. Yamamoto, T. Miyakoshi, T. Uryu (2000). Specific biological activities of Chinese lacquer polysaccharides. Carbohydrate Polymers, 43, 47-54

[174] K. Hattori, T. Yoshida, H. Nakashima, M. Premanathan, R. Aragaki, T. Mimura, Y. Kaneko, N. Yamamoto, T. Uryu (1998). Synthesis of sulfonated amino-polysaccharides having anti-VIH and blood anticoagulant activities. Carbohydrate Research, 312, 1-8

[175] N. Seddiki, E. Mbemba, D. Letourneur, L. Ylisastigui, A. Benjouad, L. Saffar, J. C. Gluckman, J. Jozefonvicz, L. Gattegno (1997). Antiviral activity of derivatized dextrans on HIV-1 infection of primary macrophages and blood lymphocytes. Biochim Biophys Acta, 1362, 47-55

[176] P. Ghosh, U. Adhikari, P. K. Ghosal, C. A. Pujol, M. J. Carlucci, E. B. Damonte, B. Ray (2004). In vitro anti-herpetic activity of sulfated polysaccharide fractions from Caulerpa racemosa. Phytochemistry, 65, 3151-3157

[177] S. K. Hobbs, W. L. Monsky, F. Yuan, W. G. Roberts, L. Griffith, V. P. Torchilin, R. K. Jain (1998). Regulation of transport pathways in tumor vessels: role of tumor type and microenvironment. Proc Natl Acad Sci U S A, 95, 4607-12

[178] R. Krishna, L. D. Mayer (2000). Multidrug resistance (MDR) in cancer. Mechanisms, reversal using modulators of MDR and the role of MDR modulators in influencing the pharmacokinetics of anticancer drugs. Eur J Pharm Sci, 11, 265-83

[179] K. K. Jain (2005). Nanotechnology-based Drug Delivery for Cancer. Technol Cancer Res Treat, 4, 407-416

[180] R. K. Jain (2001). Delivery of molecular medicine to solid tumors: lessons from in vivo imaging of gene expression and function. J Control Release, 74, 7-25

[181] I. Brigger, C. Dubernet, P. Couvreur (2002). Nanoparticles in cancer therapy and diagnosis. Adv Drug Deliv Rev, 54, 631-651

[182] T. Minko, S. S. Dharap, R. I. Pakunlu, Y. Wang (2004). Molecular targeting of drug delivery systems to cancer. Curr Drug Targets, 5, 389-406

[183] P. Couvreur, C. Vauthier Nanotechnology in pharmacology. Submitted,

[184] L. Qi, Z. Xu, X. Jiang, Y. Li, M. Wang (2005). Cytotoxic activities of chitosan nanoparticles and copper-loaded nanoparticles. Bioorganic \& Medicinal Chemistry Letters, 15, 1397-1399

[185] D. Berry, D. M. Lynn, R. Sasisekharan, R. Langer (2004). Poly(b-amino ester)s promote cellular uptake of heparin and cancer cell death. Chemistry \& Biology, 11, 487-498

[186] R. J. Linhardt (2004). Heparin-induced cancer cell death. Chemistry \& Biology, 11, 420-422

[187] Y. Peng, L. Zhang, F. Zeng, J. F. Kennedy (2005). Structure and antitumor activities of the watersoluble polysaccharides from Ganoderma tsugae mycelium. Carbohydrate Polymers, 59, 385392

[188] M. Zhang, L. Zhang, P. C. K. Cheung, V. E. C. Ooi (2004). Molecular weight and anti-tumor activity of the water-soluble polysaccharides isolated by hot water and ultrasonic treatment from the sclerotia and mycelia of Pleurotus tuber-regium. Carbohydrate Polymers, 56, 123128

[189] S.-H. Yoo, E. J. Yoon, J. Cha, H. G. Lee (2004). Antitumor activity of levan polysaccharides from selected microorganisms. International Journal of Biological Macromolecules, 34, 37-41

[190] J. C. K. Ho, M. A. Konerding, A. Gaumann, M. Groth, W. K. Liu (2004). Fungal polysaccharopeptide inhibits tumor angiogenesis and tumor growth in mice. Life Sciences, 75 , 1343-1356 
Author version from Vauthier et al., In "Handbook of Pharmaceutical Biotechnology", 2007. https://doi.org/10.1002/9780470117118.ch1d

[191] J.-J. Cheng, N.-K. Huang, T.-T. Chang, D. Ling Wang, M.-K. Lu (2005). Study for anti-angiogenic activities of polysaccharides isolated from Antrodia cinnamomea in endothelial cells. Life Sciences, 76, 3029-3042

[192] Y. Peng, L. Zhang, F. Zeng, Y. Xu (2003). Structure and antitumor activity of extracellular polysaccharides from mycellium. Carbohydrate Polymers, 54, 297-303

[193] A. V. Kabanov, E. V. Batrakova, D. W. Miller (2003). Pluronic block copolymers as modulators of drug efflux transporter activity in the blood-brain barrier. Adv Drug Deliv Rev, 55, 151-164

[194] Y. Saima, K. K. Sarkar, A. K. Sen Sr, P. Sur (2000). An antitumor pectic polysaccharide from Feronia limonia. Int J Biol Macromol, 27, 333-335

[195] A. W. Clowes, M. J. Karnowsky (1977). Supression by heparin of smooth muscle cell proliferation in injured arteries. Nature, 265, 625-626

[196] D. Logeart, S. Prigent-Richard, C. Boisson-Vidal, F. Chaubet, P. Durand, J. Jozefonvicz, D. Letourneur (1997). Fucans, sulfated polysaccharides extracted from brown seaweeds, inhibit vascular smooth muscle cell porliferation. II. Degradation and molecular weight effect. European Journal of Cell Biology, 74, 385-390

[197] D. Logeart, S. Prigent-Richard, J. Jozefonvicz, D. Letourneur (1997). Fucans, sulfated polysaccharides extracted from brown seaweeds, inhibit vascular smooth muscle cell porliferation. I. Comparison with heparin for antiproliferative activity, binding and internalization. European Journal of Cell Biology, 74, 376-384

[198] P. Mestries, C. Borchiellini, C. Barbaud, A. Duchesnay, Q. Escartin, D. Barritault, J. P. Caruelle, P. Kern (1998). Chemicaly modified dextrans modulate expression of collagen phenotype by cultured smooth muscle cells in relation to the degree of carboxymethyl, benzylamide, and sulfation substitution. J Biomed Mater Res, 42, 286-294

[199] J. M. Chupa, A. M. Foster, S. R. Summer, S. V. Madihally, W. T. Matthew (2000). Vascular cell response to polysaccharide materials: in vitro and in vivo evaluations. Biomaterials, 21, 23152322

[200] N. Sato, F. Nakazawa, T. Ito, T. Hoshino, E. Hoshino (2003). The structure of the antigenic polysaccharide produced by Eubactrium saburreum T15. Carbohydrate Research, 338, 923930

[201] A. I. Fattom, G. Horwith, S. Fuller, M. Propst, R. Naso (2004). Development of StaphVAX ${ }^{\mathrm{TM}}$, a polysaccharide conjugate vaccine against $\mathrm{S}$. aureus infection: from the lab bench to phase III clinical trials. Vaccine, 22, 880-887

[202] M. Menzel, B. Muellinger, N. Weber, K. Haeussinger, L. Ziegler-Heitbrock (2005). Inhalative vaccination with pneumococcal polysaccharide in healthy volunteers. Vaccine, 23, 5113-5119

[203] F. L. Ruben, J. E. Froeschle, C. Meschievitz, K. Chen, J. George, M. K. Reeves-Hoché, P. Pietrobon, M. Bybel, W. C. Livingood, L. Woodhouse (2001). Choosing a route of administration for quadrivalent menigococcal polysaccharide vaccine: intramuscular versus subcutaneous. Clinical Infectious Diseases, 32, 170-172.

[204] G. R. Moe, S. Tan, D. M. Granoff (1999). Molecular mimetics of polysaccharide epitopes as vaccine candidates for prevention of Neisseria meningitidis serogroup B disease. FEMS Immunology and Medical Microbiology, 26, 209-226

[205] N. Westerfeld, R. Zurbriggen (2005). Peptides delivered by immunostimulating reconstituted influenza virosomes. J Pept Sci, 11, 707-712

[206] C. Moser, I. C. Metcalfe, J. F. Viret (2003). Virosomal adjuvanted antigen delivery systems. Expert Rev Vaccines, 2, 189-196

[207] R. L. Garcea, L. Gissmann (2004). Virus-like particles as vaccines and vessels for the delivery of small molecules. Curr Opin Biotechnol, 15, 513-517

[208] B. Morein, K. F. Hu, I. Abusugra (2004). Current status and potential application of ISCOMs in veterinary medicine. Adv Drug Deliv Rev, 56, 1367-1382

[209] J. Kreuter (1995). Nanoparticles as adjuvants for vaccines. Pharm Biotechnol, 6, 463-472 
Author version from Vauthier et al., In "Handbook of Pharmaceutical Biotechnology", 2007. https://doi.org/10.1002/9780470117118.ch1d

[210] M. Koping-Hoggard, A. Sanchez, M. J. Alonso (2005). Nanoparticles as carriers for nasal vaccine delivery. Expert Rev Vaccines, 4, 185-196

[211] C. Chauvierre, P. Couvreur, D. Labarre, C. Vauthier, Copolymères à structure séquencée composé d'un segment saccharidique lié à au moins un segment hydrophobe bioérodable et particules correspondantes, 24 May 2002, Patent $n^{\circ}$ WO 02/399-79

[212] S. Salek-Ardakani, J. R. Arrand, D. Shaw, M. Mackett (2000). Heparin and heparan sulfate bind interleukin-10 and modulate its activity. Blood, 96, 1879-1888

[213] E. J. Bland, T. Keshavarz, C. Bucke (2004). The influence of small oligosaccharides on the immune system. Carbohydrate Research, 339, 1673-1678

[214] B. P. da Silva, J. P. Parente (2003). Bioactive polysaccharides from Costus spicatus. Carbohydrate Polymers, 51, 239-242

[215] L. Gan, S. H. Zhang, Q. Liu, H. B. Xu (2003). A polysaccahride-protein complex from Lyciul barbarum upregukates cytokine expression in human peripheral blood mononuclear cells. European Journal of Pharmacology, 471, 217-222

[216] G. Zhao, J. Kan, Z. Li, Z. Chen (2005). Structural features and immunological activity of a polysaccharide from Dioscorea opposita Thunb roots. Carbohydrate Polymers, 61, 125-131

[217] G. Peluso, O. Petillo, M. Ranieri, M. Santin, L. Ambrosio, D. Calabro, B. Avallone, G. Balsamo (1994). Chitosan-mediated stimulation of macrophage function. Biomaterials, 15, 1215-1220

[218] Y. Han, L. Zhao, Z. Yu, J. Feng, Q. Yu (2005). Role of mannose receptor in oligochitosanmediated stimulation of macrophage function. International Immunopharmacology, 5, 15331542

[219] P. R. Klokkevold, H. Fukayama, E. C. Sung, C. N. Bertolami (1999). The effect of chitosan (poly-Nacetyl glucosamine) on lingual hemostasis in heparinized rabbits. J Oral Maxillofac Surg, 57, 49-52

[220] R. Jordan, D. Beeler, R. Rosenberg (1979). Fractionation of low molecular weight heparin species and their interaction with antithrombin. The journal of Biological Chemistry, 254, 2902-2913

[221] S. Zeerleder, T. Mauron, B. Lämmle, W. A. Wuillemin (2002). Effect of low molecular weight dextran sulfate on coagulation and platelet function tests. Thrombosis Research, 105, 441-446

[222] M. Mauzac, J. Jozefonvicz (1984). Anticoagulant activity of dextra derivatives. Part I : synthesis and characterization. Biomaterials, 5, 301-304

[223] D. Magel-Din Hussein, W. A. Helmy, H. M. Salem (1998). Biological activities of some galactomannans and their sulfated derivatives. Phytochemistry, 48, 479-484

[224] S. Alban, A. Schauerte, G. Franz (2002). Anticoagulant sulfated polysaccharides: Part I. Synthesis and structure-activity relationship of new pullulan sulfates. Carbohydrate Polymers, 47, 267276

[225] L. Krentsel, F. Chaubet, A. Rebrov, J. Champion, I. Ermakov, P. Bittoun, S. Fermandjian, A. Litmanovich, N. Plate, J. Jozefonvicz (1997). Anticoagulant activity of functionalized dextrans. Structure analyses of carboxymethylated dextran and first Monte Carlo simulations. Carbohydrate Polymers, 33, 63-71

[226] H. Ronghua, D. Yumin, Y. Jianhong (2003). Preparation and anticoagulant activity of carboxybutyrylated hydroxyethyl chitosan sulfates. Carbohydrate Polymers, 51, 431-438

[227] A. K. Siddhanta, M. Shanmugam, K. H. Mody, A. M. Goswami, B. K. Ramavat (1999). Sulphated polysaccharides of Codium dwarkense Boergs. from the west coast of India: chemical composition and blood anticoagulant activity. Int J Biol Macromol, 26, 151-154

[228] B. P. Ross, I. Toth (2005). Gastrointestinal absorption of heparin by lipidization or coadministration with penetration enhancers. Curr Drug Deliv, 2, 277-287

[229] M. Rajaonarivony, C. Vauthier, G. Couarraze, F. Puisieux, P. Couvreur (1993). Development of a new drug carrier made from alginate. J Pharm Sci, 82, 912-917 
Author version from Vauthier et al., In "Handbook of Pharmaceutical Biotechnology", 2007. https://doi.org/10.1002/9780470117118.ch1d

[230] A. Vila, A. Sanchez, M. Tobio, P. Calvo, M. J. Alonso (2002). Design of biodegradable particles for protein delivery. Journal of Controlled Release, 78, 15-24

[231] S. Sakuma, M. Hayashi, M. Akashi (2001). Design of nanoparticles composed of graft copolymers for oral peptide delivery. Adv Drug Deliv Rev, 47, 21-37

[232] M. J. Alonso, A. Sanchez (2003). The potential of chitosan in ocular drug delivery. J Pharm Pharmacol, 55, 1451-63

[233] I. Behrens, A. I. V. Pena, M. J. Alonso, T. Kissel (2002). Comparative uptake studies of bioadhesive and non-bioadhesive nanoparticles in human intestinal cell lines and rats: the effect of mucus on particle adsorption and transport. Pharmaceutical Research, 19, 1185-1193

[234] S. Mao, O. Germershaus, D. Fischer, T. Linn, R. Schnepf, T. Kissel (2005). Uptake and Transport of PEG-Graft-Trimethyl-Chitosan Copolymer-Insulin Nanocomplexes by Epithelial Cells. Pharmaceutical Research, in press

[235] R. Fernandez-Urrusuno, P. Calvo, C. Remunan-Lopez, J. L. Vila-Jato, M. J. Alonso (1999). Enhancement of Nasal Absorption of Insulin Using Chitosan Nanoparticles. Pharmaceutical Research, 16, 1576-1581

[236] O. Borges, G. Borchard, J. C. Verhoef, A. de Sousa, H. E. Junginger (2005). Preparation of coated nanoparticles for a new mucosal vaccine delivery system. Int J Pharm, 299, 155-166

[237] K. L. Douglas, M. Tabrizian (2005). Effect of experimental parameters on the formation of alginate-chitosan nanoparticles and evaluation of their potential application as DNA carrier. J Biomater Sci Polym Ed, 16, 43-56

[238] X. W. Li, D. K. L. Lee, A. S. C. Chan, H. O. Alpar (2003). Sustained expression in mammalian cells with DNA complexed with chitosan nanoparticles. Biochimica et Biophysica Acta (BBA) - Gene Structure and Expression, 1630, 7-18

[239] J. Peng, X. Xing, K. Wang, W. Tan, X. He, S. Huang (2005). Influence of anions on the formation and properties of chitosan-DNA nanoparticles. J Nanosci Nanotechnol, 5, 713-717

[240] S. Mansouri, Y. Cuie, F. Winnik, Q. Shi, P. Lavigne, M. Benderdour, E. Beaumont, J. C. Fernandes (2006). Characterization of folate-chitosan-DNA nanoparticles for gene therapy. Biomaterials, 27, 2060-2065

[241] M. N. V. Ravi Kumar, M. Samedt, S. S. Mohapatra, X. Kong, R. F. Lockey, U. Bakowsky, G. Lindenblatt, H. Schmidt, C. M. Lehr (2004). Cationic silica nanoparticles as gene carriers: synthesis, characterization and transfection efficiency in vitro and in vivo. J Nanosci Nanotechnol, 4, 876-881

[242] I. Messai, D. Lamalle, S. Munier, B. Verrier, Y. Ataman-Onal, T. Delair (2005). Poly(D,L-lactic acid) and chitosan complexes: interactions with plasmid DNA. Colloids and Surfaces A: Physicochemical and Engineering Aspects, 255, 65-72

[243] A. Zimmer (1999). Antisense Oligonucleotide Delivery with Polyhexylcyanoacrylate Nanoparticles as Carriers. Methods, 18, 286-295

[244] H. P. Zobel, J. Kreuter, D. Werner, C. R. Noe, G. Kumel, A. Zimmer (1997). Cationic polyhexylcyanoacrylate nanoparticles as carriers for antisense oligonucleotides. Antisense \& Nucleic Acid Drug Development, 7, 483-493

[245] I. Aynie, C. Vauthier, H. Chacun, E. Fattal, P. Couvreur (1999). Spongelike alginate nanoparticles as a new potential system for the delivery of antisense oligonucleotides. Antisense Nucleic Acid Drug Dev, 9, 301-312

[246] A. El-Aneed. An overview of current delivery systems in cancer gene therapy (2004). J Control Release. 94, 1-14.

[247] A. Riggs (1981) Preparation of blood hemoglobins of vertebrates, Methods Enzymol. 76, 5-29.

[248] C. Chauvierre, M. C. Marden, C. Vauthier, D. Labarre, C. P,L. Leclerc (2004). Heparin coated poly(alkylcyanoacrylate) nanoparticles coupled to hemoglobin: a new oxygen carrier. Biomaterials, 24, 3081-3086 
Author version from Vauthier et al., In "Handbook of Pharmaceutical Biotechnology", 2007. https://doi.org/10.1002/9780470117118.ch1d

[249] A.J. Khopade, S. Khopade, N.K. Jain (2002). Development of hemoglobin aquasomes from spherical hydroxyapatite cores precipitated in the presence of half-generation poly(amidoamine) dendrimer. Int. J. Pharm. 241, 145-154. 